\title{
Evolutionary history of the Maltese wall lizard Podarcis filfolensis: insights on the 'Expansion-Contraction' model of Pleistocene biogeography
}

\author{
DANIELE SALVI,* PATRICK J. SCHEMBRI,† ARNOLD SCIBERRAS $\$$ and D. JAMES HARRIS* \\ *CIBIO, Centro de Investigação em Biodiversidade e Recursos Genéticos, Campus Agrário de Vairão, 4485-661 Vairão, Portugal, \\ $\dagger$ Department of Biology, University of Malta, Msida MSD2080 Malta, \$133, Arnest, Arcade Str., Paola, Malta
}

\begin{abstract}
The expansion-contraction (EC) model predicts demographic and range contraction of temperate species during Pleistocene glaciations as a consequence of climate-related habitat changes, and provides a paradigm for explaining the high intraspecific diversity found in refugia in terms of long-term demographic stability. However, recent evidence has revealed a weak predictive power of this model for terrestrial species in insular and coastal settings. We investigated the Pleistocene EC dynamics and their evolutionary consequences on temperate species using the Maltese archipelago and its endemic lizard Podarcis filfolensis as a model system. The evolutionary and demographic history of $P$. filfolensis as inferred from mitochondrial and nuclear sequences data does not conform to the EC model predictions, supporting (i) demographic and spatial stability or expansion, rather than contraction, of the northern and southern lineages during the last glacial period; and (ii) a major role for allopatric differentiation primed by sea-level dynamics, rather than prolonged demographic stability, in the formation of the observed genetic diversity. When combined with evidence from other Mediterranean refugia, this study shows how the incorporation of Pleistocene sea-level variations in the EC model accounts for a reverse demographic and range response of insular and coastal temperate biotas relative to continental ones. Furthermore, this cross-archipelago pattern in which allopatric diversity is formed and shaped by EC cycles resembles that seen between isolated populations within mainland refugia and suggests that the EC model, originally developed to explain population fluctuations into and out-of refugia, may be appropriate for describing the demographic and evolutionary dynamics driving the high genetic diversity observed in these areas.
\end{abstract}

Keywords: Allopatric divergence, genetic diversity, glacial expansion, historical demography, Mediterranean islands, phylogeography

Received 31 August 2012; revision received 30 December 2013; accepted 9 January 2014

\section{Introduction}

Understanding the relationships between geographical patterns of distribution of biological diversity and evolutionary processes is a central and longstanding goal for evolutionary biogeography. In the last decades, the combination of palaeontological, palaeoclimatic and phylogeographical studies has provided important

Correspondence: Daniele Salvi, Fax: +351 252 661780;

E-mail: danielesalvi.bio@gmail.com insights in this respect, highlighting the key role of Pleistocene climatic oscillations in structuring the present-day biodiversity patterns at the regional and global scale (Hewitt 1996, 2000, 2004; Taberlet et al. 1998; Schmitt 2007; Hickerson et al. 2010).

During the Pleistocene climatic cycles, species were greatly affected both by the advance and retreat of the continental ice sheets and consequent climate-related changes in habitat, and by the sea-level fluctuations associated with global ice-volume changes. These climatedriven changes imposed a cyclic contraction-expansion 
of terrain and habitats, with a consequent and parallel contraction and expansion of species' ranges. This 'expansion-contraction' (EC) model (Provan \& Bennet 2008) has been empirically corroborated for the terrestrial flora and fauna of North America and Europe by a vast body of evidence from fossils, pollen records and comparative phylogeographical studies (see Huntley \& Birks 1983; Bennett et al. 1991; Williams et al. 1998; for a review see Hewitt 2004; Schmitt 2007). For temperate species (sensu Stewart \& Dalén 2008; including 'Continental' and 'Mediterranean' elements sensu Schmitt 2007), this model provides a demographic scenario of size and range contraction with a shift to southern refugia during glacials, followed by postglacial population growth and northwards recolonization (Hewitt 1996; Provan \& Bennet 2008).

However, although the basic mechanism of the EC model is straightforward, the application of this model in regional contexts has revealed a complexity of additional factors shaping population demography and species ranges. Over the last decade, a plethora of patterns of diversity and phylogeographical paradigms have been invoked to account for such a complexity of EC processes allowing the refining and extension of earlier models and scenarios of Pleistocene EC dynamics (reviewed in: Stewart \& Lister 2001; Gómez \& Lunt 2007; Schmitt 2007; Provan \& Bennet 2008; Stewart et al. 2010; Nieto Feliner 2011; Schmitt \& Varga 2012).

In particular, two outstanding issues have arisen from studies on the evolutionary and demographic dynamics of populations from coastal areas and refugia. First, it has been suggested that some temperate species inhabiting Mediterranean coastal areas could have maintained stable populations or even experienced range/demographic expansions during glacials as a consequence of the synergistic effect of the increased availability of terrestrial habitat brought about by drops in the sea-level and the mild coastal microclimates due to the buffering action of the sea (Canestrelli et al. 2007; Canestrelli \& Nascetti 2008; Bisconti et al. 2011). Second, the complex topography and palaeogeographical development of many southern refugia suggested that contraction-expansion of habitat may have operated at a regional scale inside refugia throughout the palaeoclimatic and palaeogeographical evolution of these areas (Gómez \& Lunt 2007; Canestrelli et al. 2010; Nieto Feliner 2011). These EC processes have led to population isolation and divergence, thus enhancing the formation of intraspecific genetic diversity (Canestrelli et al. 2010; Vega et al. 2010; Nieto Feliner 2011). Understanding the temporal context of the EC dynamics in coastal settings and their contribution at a regional scale in the formation of this genetic diversity has important consequences for our understanding of Pleistocene biogeography and current patterns of biological diversity.

The investigation of both 'glacial expansion' of coastal populations and regional EC dynamics is often problematic in continental species for several reasons, including (i) the need for intense sampling in coastal areas and putative refugia, which is not always feasible in studies at the scale of the whole species range, (ii) the situation when entire coastal and refugial areas that existed during glacial periods were re-flooded during the following interglacial, and (iii) the occurrence of secondary contact and admixture between lineages from different refugia, which can erase any local genetic imprints of past demographic expansion and EC dynamics.

Mediterranean islands constitute a promising setting for investigating the occurrence of (coastal) glacial expansions of temperate species and the evolutionary consequences of EC dynamics because (i) climate change was attenuated (Thiede 1978), thus allowing the survival of at least a portion of the insular biota also during glacial cooling, (ii) islands have a broad expanse of coastline along which the availability of terrestrial habitats dramatically increased during glacial sea-level lowstands, and (iii) sea-level glacial/interglacial oscillations encapsulate a pure EC dynamic of insular habitats due to fluctuating island size. In this respect, terrestrial species inhabiting archipelagos where islands are separated by short stretches of shallow water provide a controlled, natural experiment on the microevolutionary and demographic processes primed by the climaterelated Pleistocene changes. Species ranges followed cycles where the population occupied a single unit of land as individual islands became connected during the sea-level lowstands during glacials, but then became fragmented into smaller populations on single islands genetically isolated by a uniform physical barrier to gene flow (the surrounding sea) as sea-levels rose during interglacial periods (see Jordan et al. 2005; Papadopoulou et al. 2009).

The Maltese archipelago and its endemic lizard Podarcis filfolensis offer an optimal model system for investigating the demographic and evolutionary consequences of past climate-related habitat contractions and expansions. The Maltese archipelago is located $96 \mathrm{~km}$ south of the Sicilian land mass and $300 \mathrm{~km}$ north of the North African coast and comprises two major islands, Malta $\left(246 \mathrm{~km}^{2}\right)$ and Gozo $\left(67 \mathrm{~km}^{2}\right)$ and with a smaller island Comino $\left(3 \mathrm{~km}^{2}\right)$ between, each surrounded by numerous islets and offshore rocks (Fig. 1). Palaeontological and palaeogeographical studies have established that the past changes in sea level 
(a)

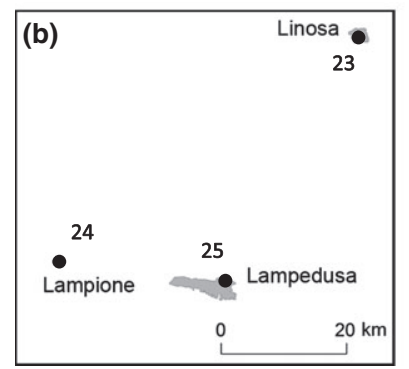

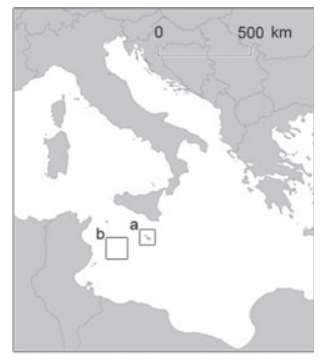

17

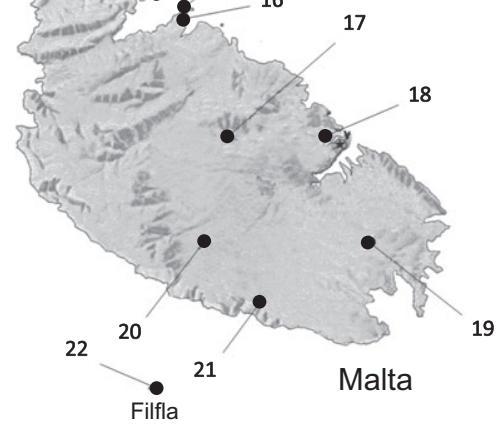
$10 \mathrm{~km}$
Fig. 1 Map of the study area showing sampling locations of the Maltese wall lizard, Podarcis filfolensis, on the Maltese (a) and the Pelagian (b) archipelagos. Detailed information on sampling localities and specimens is found in Table 1. that started following the Zanclean transgression at the end of the Messinian, approximately 5.33 Mya, and continued during the Plio-Pleistocene glacial/interglacial cycles, have been responsible for the assembly and evolution of the Maltese biota (reviewed in Hunt \& Schembri 1999; Pedley et al. 2002, 2007; Schembri 2003). Indeed, the southern Mediterranean location of the Maltese Islands and the surrounding sea buffered considerably the Maltese climate during periods of glacial cooling (Thiede 1978; Schembri 1997; Hunt \& Schembri 1999). Therefore, climate probably played a subordinate role in biogeographical and evolutionary dynamics of the Maltese biota relative to eustatic sealevel changes, while the contribution of tectonic phenomena can be ruled out since major tectonic movement of the Maltese archipelago ceased around 1.6 Mya (Pedley 2011), and regional uplift completed by 125 kya during the MIS 5 (Pedley et al. 2002; Pedley 2011). Past sea-level changes caused repeated connection and separation of individual Maltese islands and pronounced change in their size and shape (Pedley et al. 2002; Micallef et al. 2013). The Maltese wall lizard $P$. filfolensis with its very limited over-sea dispersal capacity is especially suitable for studying the demographic and evolutionary effects of such dynamics as it occurs on all islands and most of the islets of the Maltese archipelago, as well as on the adjacent
Pelagian Islands (Lampedusa, Linosa and Lampione), which are part of the same geological unit as the Maltese Islands and, except for the volcanic Linosa, share the same geological and geographical history (Pedley et al. 1978; Pedley 1990; Gatt 2007). Moreover, the phylogenetic relationships between Sicilian and Maltese Podarcis species and the palaeogeographical connections between the Maltese Islands and Sicily are well established (Pedley et al. 2002; Harris et al. 2005), allowing inferences to be made regarding tempo and mode of the biogeographical origin of $P$. fifolensis. Furthermore, a study of the allozyme variation of five populations of this species (Capula 1994a) revealed high genetic polymorphism but low interpopulation divergence, which may be consistent with a Pleistocene evolutionary scenario.

In this study, we investigated the phylogeography and historical demography of the Maltese wall lizard using both mitochondrial and nuclear genetic markers. Our aims were (i) to establish the temporal and spatial context of population EC dynamics, (ii) to assess whether diversity patterns in this Mediterranean insular system have been shaped mainly by climatic or sealevel Pleistocene oscillations and (iii) to discuss our findings in the context of the formation of patterns of genetic diversity and distribution of temperate biota in coastal and refugial areas. 


\section{Materials and methods}

\section{Study species}

The Maltese wall lizard, Podarcis filfolensis (Bedriaga 1876), is a polytypic species endemic to the Maltese and Pelagian archipelagos (see Fig. 1 and Table 1). Five nominal subspecies of $P$.filfolensis are currently recognized: P.f. filfolensis (Bedriaga 1876) on Filfla islet (off Malta), P.f. maltensis Mertens, 1921 on Malta, Gozo (=Ghawdex) and Comino (=Kemmuna), P.f. generalensis (Gulia 1914) on Fungus Rock islet (=General's Rock = Il-Hagra tal-General) (off Gozo), P.f. kieselbachi (Fejervary 1924) on Selmunett islet (=St Paul's Islands = Il-Gzejer ta' San Pawl), and P. f. laurentiimuelleri (Fejervary 1924) originally on the Pelagian islands Linosa and Lampione, where it may not be native (Capula 1994a), and recently introduced to Lampedusa (Lo Cascio et al. 2005). The population on Cominotto islet (= Kemmunett) (off Comino) has been regarded as a distinct subspecies, but has not been named (Savona Ventura 1983).

\section{Sample collection and laboratory procedures}

In total, 98 Maltese wall lizards were collected from 25 sampling sites spanning all the main islands of the
Maltese and Pelagian archipelagos and every islet and offshore rock where this species occurs. Thus, our sampling includes all the five named subspecies, the subspecies inquirenda from Cominotto and the supposedly introduced populations from the Pelagian Islands of Lampedusa, Lampione and Linosa. The geographical location of each sample is reported in Table 1 and shown in Fig. 1, and the sample size for each analysed gene is reported in Table 2. In addition, two samples of $P$. wagleriana from mainland Sicily and of P. raffonei from the Aeolian archipelago (Sicily) were included in the analyses. Tail tips were removed from field-collected lizards and stored in $96 \%$ ethanol; afterwards, all the lizards were released at the capture point.

Total genomic DNA was extracted from tail muscle following standard high-salt protocols (Sambrook et al. 1989). Portions of four genes were amplified by polymerase chain reaction: the mitochondrial NADH dehydrogenase subunit 4 with flanking tRNAs tRNA ${ }^{\text {Ser }}$, tRNA $^{\text {His }}$ and tRNA ${ }^{\text {Leu }}$ (hereafter $n d 4$ ), and three nuclear fragments, the Melanocortin receptor 1 (hereafter $m c 1 r$ ) and the anonymous loci pod15b and pod55 (Pereira et al. 2013). The primers used for amplification and respective references are reported in Table 3. Amplifications were conducted following conditions described in previous studies [nd4: Salvi et al. (2010); mc1r: Pinho et al. (2010);

Table 1 Geographical location and taxonomy of the 25 populations of Podarcis filfolensis used in this study

\begin{tabular}{|c|c|c|c|c|}
\hline Sample & Subspecies & Locality* & Longitude & Latitude \\
\hline 1 & P.f. maltensis & Wied il-Ghasri, Gozo Island & 14.225 & 36.072 \\
\hline 2 & P.f. maltensis & Ramla 1-Hamra, Gozo Island & 14.281 & 36.060 \\
\hline 3 & P.f. generalensis & Fungus Rock Islet & 14.188 & 36.046 \\
\hline 4 & P.f. maltensis & Ggantija, Gozo Island & 14.266 & 36.045 \\
\hline 5 & P.f. maltensis & Ta' Sarraflu, Gozo Island & 14.209 & 36.037 \\
\hline 6 & P.f. maltensis & Gebla tal-Halfa Islet & 14.337 & 36.027 \\
\hline 7 & P.f. maltensis & Tac-Cawl Islet & 14.321 & 36.024 \\
\hline 8 & P.f. maltensis & Ta' Cenc, Gozo Island & 14.251 & 36.018 \\
\hline 9 & P.f. maltensis & Mgarr ix-Xini, Gozo Island & 14.272 & 36.018 \\
\hline 10 & P. f. subsp. inquirenda & Cominotto Islet (Kemmunett) & 14.320 & 36.013 \\
\hline 11 & P.f. maltensis & Il-Bibien (larger) Islet & 14.326 & 36.011 \\
\hline 12 & P.f. maltensis & Comino Island (Kemmuna) & 14.342 & 36.011 \\
\hline 13 & P.f. maltensis & Il-Bibien (smaller) Islet & 14.328 & 36.009 \\
\hline 14 & P. f. kieselbachi & Selmunett Islet (St. Paul's Islet) & 14.407 & 35.966 \\
\hline 15 & P.f. maltensis & Ta' Fra Ben, Malta Island & 14.425 & 35.960 \\
\hline 16 & P.f. maltensis & Qawra, Malta Island & 14.425 & 35.955 \\
\hline 17 & P.f. maltensis & Balzan, Malta Island & 14.450 & 35.901 \\
\hline 18 & P.f. maltensis & Manoel Island, Malta Island & 14.507 & 35.902 \\
\hline 19 & P.f. maltensis & Zejtun, Malta Island & 14.532 & 35.853 \\
\hline 20 & P.f. maltensis & Siggiewi, Malta Island & 14.437 & 35.854 \\
\hline 21 & P.f. maltensis & Zurrieq, Malta Island & 14.469 & 35.825 \\
\hline 22 & P.f. filfolensis & Filfla Islet & 14.409 & 35.787 \\
\hline 23 & P. f. laurentiimuelleri & Linosa Island & 12.867 & 35.864 \\
\hline 24 & P. f. laurentiimuelleri & Lampione Islet & 12.317 & 35.550 \\
\hline 25 & P. f. laurentiimuelleri & Lampedusa Island & 12.595 & 35.509 \\
\hline
\end{tabular}

*Islands with surface area $<1 \mathrm{~km}^{2}$ are designated as islets. 


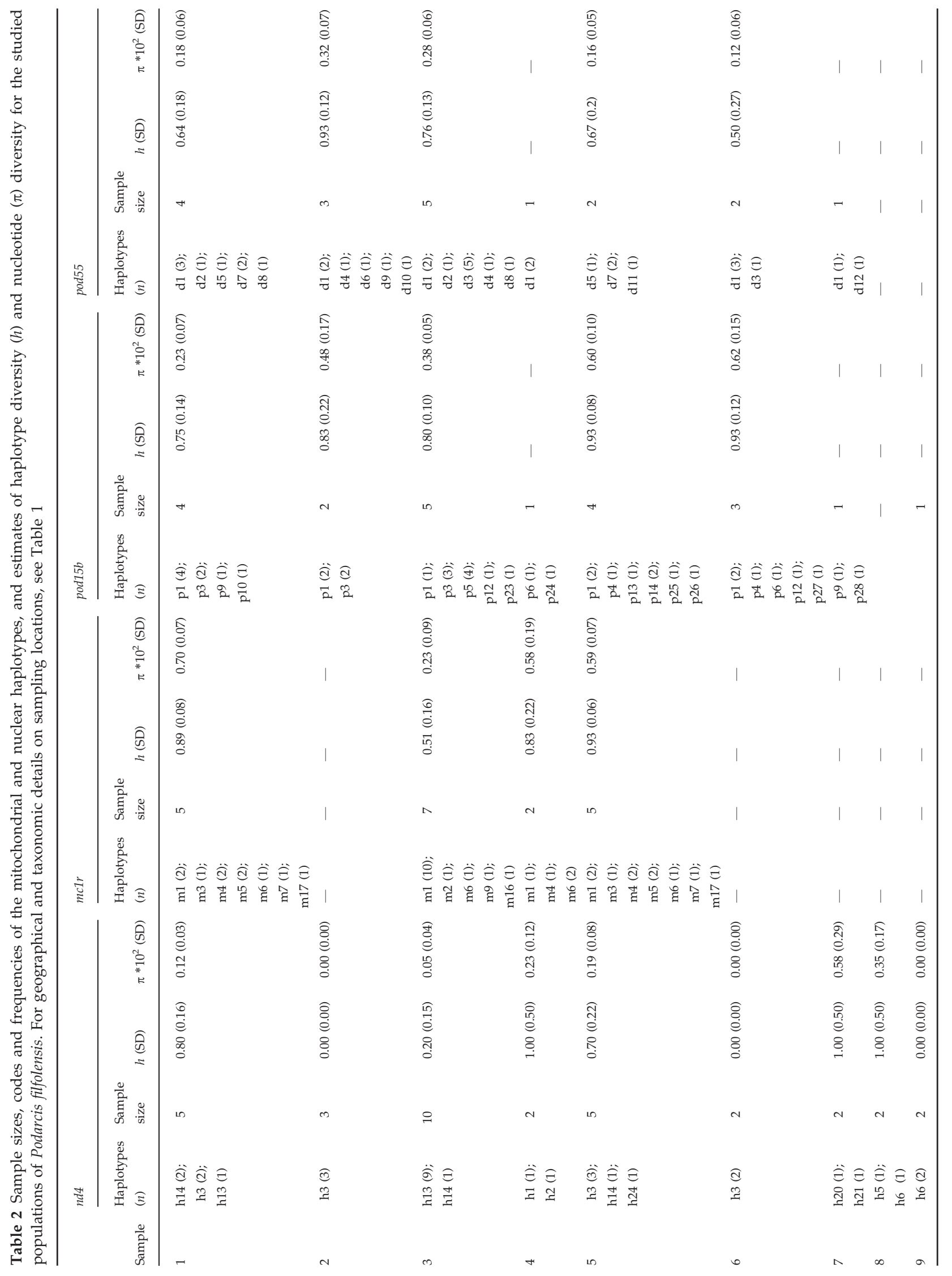


D. SALVI ET AL.

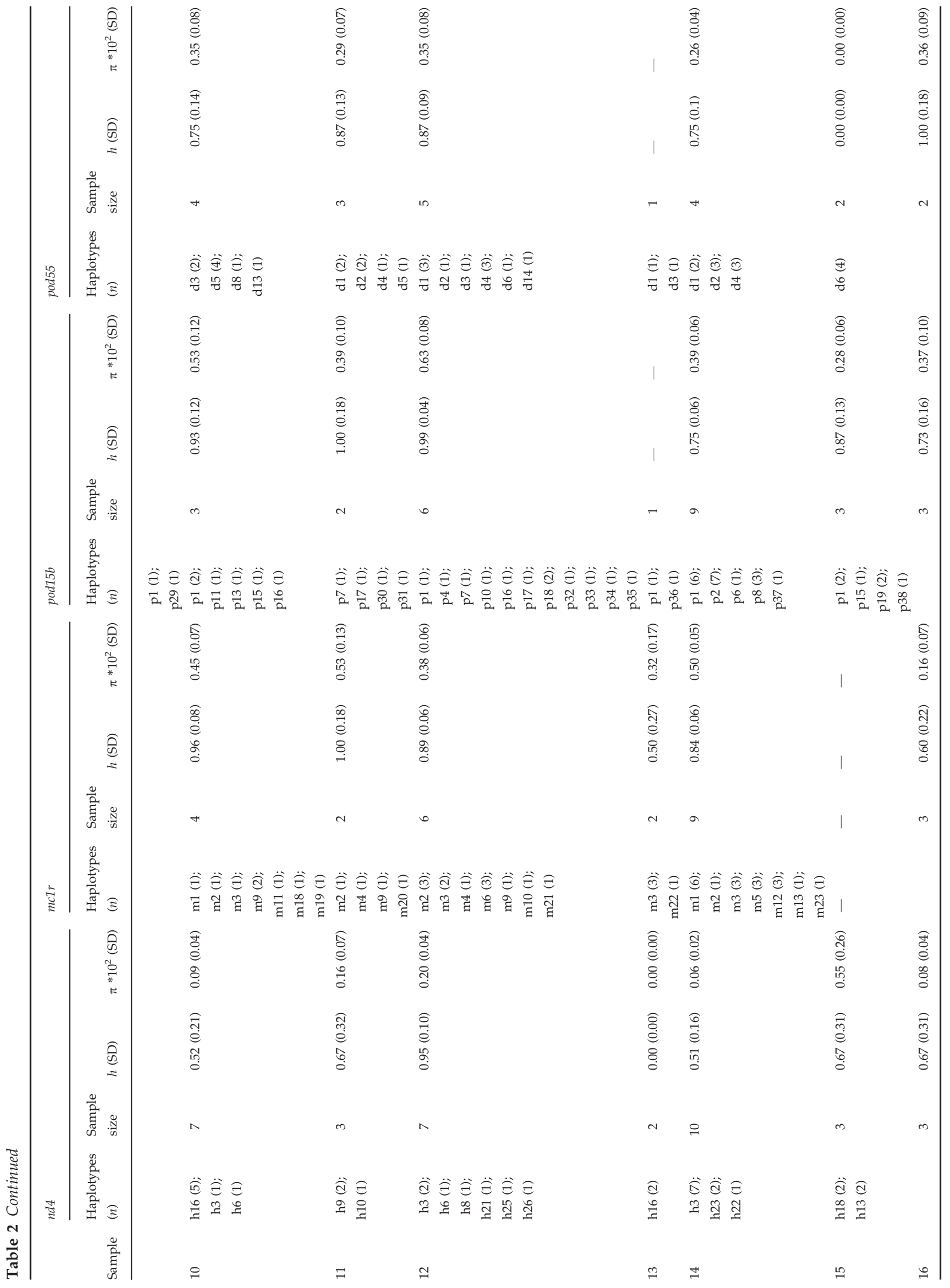




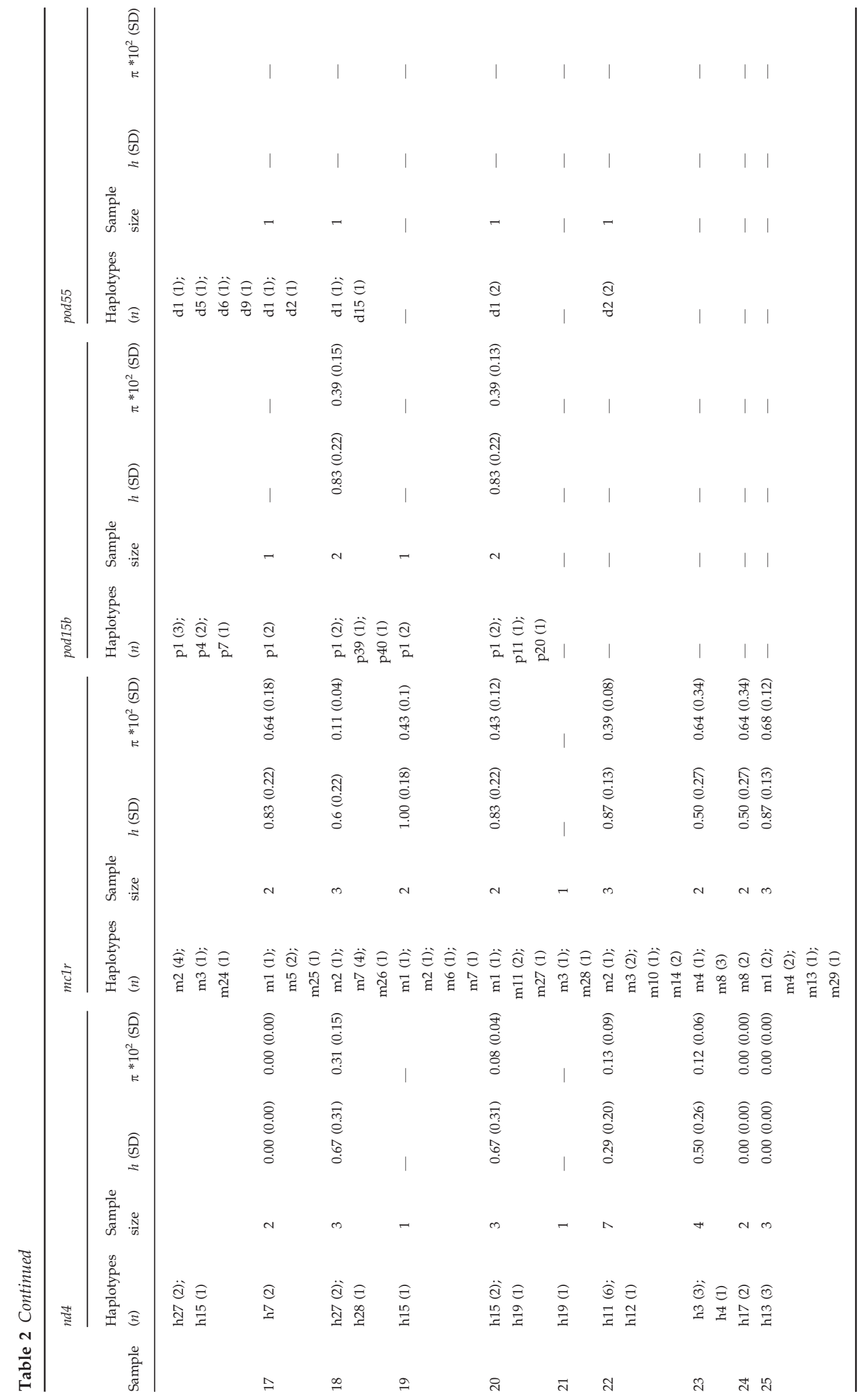


Table 3 Primers used in this study

\begin{tabular}{|c|c|c|c|}
\hline Gene & Primer & Primer sequence & Reference \\
\hline \multirow[t]{2}{*}{$n d 4$} & ND4 & $5^{\prime}$ - CAC CTA TGA CTA CCA AAA GCT CAT GTA GAA GC - 3' & \multirow[t]{2}{*}{ Arévalo et al. (1994) } \\
\hline & Leu & 5' - CAT TAC TTT TAC TTG GAA TTT GCA CCA - 3' & \\
\hline \multirow[t]{2}{*}{$m c 1 r$} & MC1RF & $5^{\prime}$ - GGCNGCCATYGTCAAGAACCGGAACC - 3' & \multirow[t]{2}{*}{ Pinho et al. (2010) } \\
\hline & MC1RR & $5^{\prime}$ - CTC CGR AAG GCR TAG ATG ATG GGG TCC AC - 3' & \\
\hline \multirow[t]{2}{*}{ pod15b } & pod15bf & $5^{\prime}$ - AAT CCT GGC TAA ATG CAA GCC TTG G - 3' & \multirow[t]{2}{*}{ Pereira et al. (2013) } \\
\hline & pod15br & 5' - GCC AGG AGA ATA AGC TAC TCC ATC C - 3' & \\
\hline \multirow[t]{2}{*}{ pod55 } & pod55f & $5^{\prime}$ - GGA TCT TTA TAG GAG AGT GCA GGC C - 3' & \multirow[t]{2}{*}{ Pereira et al. (2013) } \\
\hline & pod55r & 5' - TTC CAG ATT GTG TTT ATC CTG GTG G - 3' & \\
\hline
\end{tabular}

pod15b, and pod55: Pereira et al. (2013)]. Purification and sequencing of PCR products were carried out by a commercial company, Macrogen (www.macrogen.com).

\section{Data analysis}

Sequences were visually checked and aligned using Bioedit v 7.1 (Hall 1999) and the Clustal X (Thompson et al. 1994) extension implemented therein. The haplotype phase of nuclear genes was inferred using the coalescent-based Bayesian algorithm in PHASE v. 2.1 (Stephens et al. 2001; Stephens \& Donelly 2003) as implemented in DnaSP v. 5.10.01 (Librado \& Rozas 2009). The possible occurrence of recombination events was assessed using the Pairwise Homoplasy Index (PHI) test (Bruen et al. 2006) implemented in SPLITSTREE v. 4 (Huson \& Bryant 2006). Sequence divergence ( $p$-uncorrected distance) was assessed using MEGA v. 5 (Tamura et al. 2011). To assess patterns of genetic diversity, we computed the number of haplotypes $(n)$, haplotype diversity $(h)$ and nucleotide diversity $(\pi)$ with their standard deviations (SD) for each gene fragment using DnaSP.

We inferred the genealogical relationships between haplotypes using a network approach, which is the most appropriate method for intraspecific gene evolution, particularly when few characters for phylogenetic analysis are available due to shallow levels of divergence (Posada \& Crandall 2001). Statistical parsimony networks were constructed under the $95 \%$ probability criterion for a parsimonious connection employing the software TCS v. 1.21 (Clement et al. 2000).

To define the genetic structure of $P$. filfolensis in the Maltese archipelago, we used the spatial analysis of molecular variance (SAMOVA) approach implemented in SAMOVA v. 1.0 (Dupanloup et al. 2002). This method allows defining groups of geographically proximate populations that are maximally differentiated from each other, through a simulated annealing procedure without the prior assumption of group composition. The program was run with 100 random initial conditions for 10,000 iterations, testing for the grouping options from a predefined number of groups $(K)=$ 2-10, excluding the samples composed of single individuals (samples 19 and 21) and the Pelagian samples (samples 23-25) as they are likely introduced (see results and discussion).

In order to estimate the time to the most recent common ancestor of $P$. filfolensis and the evolutionary rate for the $n d 4$ fragment, we used the least-squares method (Xia \& Yang 2011) as implemented in DAMBE v. 5.2 (Xia \& Xie 2001). This distance-based method allows a fast and accurate estimate of divergence times, providing the data set conforms to the molecular clock hypothesis and a proper substitution model is used for estimating distances (Xia \& Yang 2011). The general time reversible (GTR) model was selected from 88 models as the best model of sequence evolution under the Akaike's information criterion (AIC) using JModeltest v. 2 (Darriba et al. 2012). The GTR model was used to generate a distance matrix from which a phylogenetic tree was derived using the neighbour-joining (NJ) method in MEGA v. 5, including P. raffonei, and the sister species $P$. wagleriana as outgroups. Using the same software, the molecular clock test was performed by comparing the maximum-likelihood (ML) value for the given topology with and without the molecular clock constraints under the GTR model. Based on this test, the null hypothesis of equal evolutionary rate throughout the tree was not rejected at a 5\% significance level. Given the possible time dependency of the molecular clock (Ho et al. 2005; but see also Bandelt 2008), we use both an old and a recent calibration point in order to minimize the bias due to rate variation across temporal scales. As calibration points, we used (i) the palaeogeographical event resulting in the isolation of the Maltese Islands group from the Sicilian landmass - and thus presumably to the vicariance between the ancestor of the Maltese lizard $P$. filfolensis from its sister species the Sicilian P. wagleriana, - and (ii) the age of the split between $P$. wagleriana and its allied species, the Aeolian wall lizard $P$. raffonei. The first vicariance event took place after the reopening of the Gibraltar Strait 5.33 Mya; during this time, a rapid refilling of the Mediterranean 
basin occurred, after desiccation during the Messinian Salinity Crisis (Krijgsman et al. 1999; Pierre et al. 2006), likely promoting vicariance and speciation in several Mediterranean groups including Podarcis lizards (Poulakakis et al. 2005; Pinho et al. 2006; Brown et al. 2008). The split between $P$. wagleriana and $P$. raffonei is much more recent and has likely occurred during the Pleistocene - about 700 kya - when the volcanic islands of the Aeolian archipelago emerged (Maramai et al. 2005) and were presumably colonized by the wagleriana-like ancestor as inferred from genetic distance data between P. wagleriana and P. raffonei by Capula (1994b). The dating procedure was performed using the previously estimated tree topology, and the composite ML genetic distance implemented in DAMBE for the Tamura-Nei substitution model (Tamura et al. 2004; Xia 2009). The use of the simultaneous estimated (SE) ML composite distance is recommended over the independently estimated (IE) distances allowed by the GTR model (Xia 2009). Confidence intervals of the time estimates were assessed by 1000 bootstrap replicates.

To check the consistency of dating results, we also estimated divergence times using the BEAST v. 1.7.4 package (Drummond et al. 2012). Although computationally more intensive than distance-based methods, BEAST allows the incorporation of the uncertainty associated with phylogenetic estimates, calibration dates and among-lineage variation of substitution rates in a single analysis (Drummond et al. 2012). We used the normal distribution to incorporate the calibration priors on the root of the tree $(\mu=5.325, \sigma=0.001)$ and on the split between $P$. wagleriana and P. raffonei $(\mu=0.695$, $\sigma=0.001)$. We performed both strict clock and lognormal relaxed clock analyses assuming the GTR model of sequence evolution and a coalescent tree prior. All BEAST analyses were run twice, with 100 million iterations per run, sampling every 10000 steps. Convergence diagnostic and summary of posterior samples of parameters were assessed in TRACER v. 1.5 (Rambaut \& Drummond 2007), and sampled trees from independent runs were combined in LogCombiner (burnin $=2500$ ). As results using strict and relaxed clock models were similar, we summarized only results based on strict clock analyses in TreeAnnotator.

The historical demography of the Maltese wall lizard was assessed by a suite of statistical tests for detecting changes in population size over time and space for the main lineages recovered by the phylogenetic and SAMOVA analyses. First we performed a demographic reconstruction by means of an Extended Bayesian Skyline Plot analysis (EBSP) implemented in BEAST. The EBSP combines information from multiple loci, thus incorporating the stochastic differences between gene genealogies in the estimation of population parameters.
As a further advantage over previous skyline methods, the EBPS approach is not constrained a priori to a specific model of historical population size change (Heled \& Drummond 2008; Ho \& Shapiro 2011). This was ensured using a Poisson prior with mean $\lambda=0.693$ for the number of population changes $(\psi)$, which places an equal probability (50\% prior weight) to a constant and to a nonconstant population size. To allow for continuous population size dynamics, a piecewise linear model was used. As the quality of sequence data is crucial for an accurate EBSP estimate of population size dynamics (Heled \& Drummond 2008), we verified consistency of results between two runs using either all the nuclear sequences or only those sequences phased with a probability higher than 0.9. The EBSP analysis was run using strict clock models, substitution models and trees unlinked across all markers. The nd4 substitution rate was set according to the estimated value in DAMBE and used as a reference to estimate relative rates for nuclear genes. Three runs each of $3 \times 10^{8}$ generations sampled at $10^{4}$ intervals were performed and checked for convergence and effective sample size of parameters (ESSs) with TRACER. The EBS plots were generated using the Python scripts provided in Heled (2010). To assess the time frame at which the EBSP reconstructions have high reliability, we generated a detailed demographic function description following Heled (2010) and we inspected the number of demographic functions which had an $X$ point at each interval of time.

Additionally, independent assessments of demographic expansion were obtained by analysing mtDNA pairwise nucleotide differences (mismatch distribution) and through Tajima's $D$ (Tajima 1989), Fu's $F_{S}$ (Fu 1997), and Ramos-Onsin and Roza's $R_{2}$ (Ramos-Onsins \& Rozas 2002) tests. Mismatch distribution analyses were carried out in ARLEQUINN v. 3.5 (Excoffier \& Lischer 2010) comparing the observed distribution of nucleotide differences between pairs of haplotypes with those expected under demographic (Rogers \& Harpending 1992) and spatial (Excoffier 2004) expansion models, using a generalized least square approach. This allowed estimation of the age of the expansion as the time in generations $t$, given the parameter $\tau$ and the mutation rate per sequence and per generation $u(\tau=2 u t)$. We used the sum of squared deviations (SSD) as goodnessof-fit statistics for the observed and expected mismatch distributions. We tested the significance of the fit of the expansion model and the confidence intervals for the associated parameters estimates using 10000 bootstrap replicates. The statistics $D, F_{\mathrm{S}}$ and $R_{2}$ were used to test for an excess of singleton mutations in each clade genealogy, which is an expected consequence of population expansion. We used DnaSP to estimate the $D, F_{S}$, and $R_{2}$ values, and we assessed their significance through 
10000 coalescent simulations under the hypothesis of population equilibrium and selective neutrality.

\section{Results}

The mitochondrial DNA sequences (855 bp) from 94 individuals from 25 populations comprised 40 variable positions. The nuclear DNA data sets consisted of 130 sequences for $m c 1 r(628 \mathrm{bp}), 108$ for $\operatorname{pod} 15 b$ (522 bp) and 86 for pod55 (416 bp) with 21, 34 and 11 polymorphic positions, respectively (see Table S1, Supporting information for GenBank accession numbers). An overview of genetic data including estimates of haplotype (h) and nucleotide $(\pi)$ diversity per locus for each population is given in Table 2. When comparing the mitochondrial diversity of samples from the three main islands (Gozo, Comino and Malta) with their neighbouring islets, higher values were observed in the former, whereas low diversity was found on islets with the exception of Tac-Cawl and Selmunett islets (Table 2). Pelagian samples showed either low values (Linosa Island) or a complete lack (Lampione and Lampedusa islands) of mitochondrial diversity. Nuclear diversity was high in most of the localities of sample size $>5$ except for the Fungus Rock islet samples where low nucleotide diversity was observed at all loci.

The phylogenetic relationships between the mitochondrial haplotypes, as inferred by the parsimony approach, are represented by a single network (maximum connection steps at $95 \%$ probability $=12$ ), which shows a clear phylogeographical structure (Fig. 2A). Twenty-six mtDNA haplotypes clustered in two main clades ( $p$-distance between lineages $=1.29 \%$ ): the Maltese clade, grouping haplotypes from most samples of Malta and Filfa (in green colours in Fig. 2A), and the Gozitan clade, grouping haplotypes from Gozo and Comino and their neighbour islets, Selmunett islet and Ta' Fra Ben (Malta) and the Pelagian islands (in blue colours in Fig. 2A). Two haplotypes, sampled in four individuals from two Maltese samples, Balzan and $\mathrm{Ta}^{\prime}$ Fra Ben (in yellow in Fig. 2A), were differentiated from both the main clades by at least 5 mutational steps. Otherwise, haplotypes within clades are connected by a maximum of three mutational steps, while a minimum of eight steps separated the two main clades. The phylogenetic networks depicting the relationships between nuclear haplotypes (maximum connection steps at $95 \%$ probability ranging from 8 to 10) and the haplotype distribution among samples show that nuclear diversity is not geographically structured (Fig. 2B). The number of nuclear haplotypes observed in each sample (with size $>2$ ) ranged from 2 to 11; most haplotypes were restricted to a single locality $(65 \%, 33 \%$ and $55 \%$, of $m c 1 r$, pod15b and pod55 haplotypes, respectively), and the remaining ones were mostly shared by the three main islands (Table 2 and Fig. 2).

The SAMOVA analysis on the mtDNA data set (Fig. 3) identified three groups of populations $(K=3)$ as the grouping option which best explains the amonggroup spatial partitioning of molecular variance. Higher values of $K$ produced genetic structures which either showed lower $F_{\mathrm{CT}}$ values (from $K>6$ ) or similar $F_{\mathrm{CT}}$ values, but their population groupings were less informative (i.e. from $K=4-6$, where one population at a time is removed from the groups structure). The threegroup genetic structure identified by the SAMOVA explains $79.30 \%$ of the overall molecular variance $\left(F_{\mathrm{CT}}=0.79 ; P<0.001\right), 7.86 \%$ was explained by differences among-populations within-group $\left(F_{\mathrm{SC}}=0.38\right.$; $P<0.001$ ), and $12.84 \%$ by differences within populations $\left(F_{\mathrm{ST}}=0.87 ; P<0.001\right)$. The population composition of the three groups strictly reflects the geographic partition of haplotype lineages, as the first group included the samples carrying Gozitan clade haplotypes (samples 1-14), the second those carrying Maltese clade haplotypes (samples 16, 18-22) and the third the samples Ta' Fra Ben and Balzan (samples 15, 17), which carried haplotypes distinct from both the main clades. SAMOVA analyses based on nuDNA data did not allow identification of a population grouping best explaining the data (see Fig. S1, Supporting information). Indeed, $F_{\mathrm{CT}}$ values never exceeded $0.22,0.24$ and 0.34 for the $m c 1 r$, pod15b and pod55 loci, respectively, whereas for the same loci, molecular variance within populations $\left(F_{\mathrm{ST}}\right)$ was above $0.70,0.71$ and 0.57 .

The age of the most recent common ancestor of the mitochondrial lineages of $P$. filfolensis estimated in DAMBE was 476 kya ( \pm 138 ky SD). Time estimates for the most recent common ancestor for the two main clades were $183 \mathrm{kya}( \pm 81 \mathrm{ky} \mathrm{SD})$ and $224 \mathrm{kya}( \pm 105 \mathrm{ky}$ SD) for the Gozitan and Maltese clades, respectively (see Fig. S2A, Supporting information). According to the calibration used, the estimated $n d 4$ substitution rate was $1.15 \%$ ( $\pm 0.12 \%$ SD) per million years. This value is in agreement with substitution rates previously proposed for Podarcis lizards for this gene fragment (Pinho et al. 2007). Dating results from BEAST were concordant with DAMBE estimates, placing the divergence between the main clades of $P$. filfolensis at 576 kya (95\% high posterior density interval: 331-848 kya) and the divergence within the Gozitan and Maltese clades at 229 (115-351) kya and 171 (65-295) kya, respectively (Fig. S2B, Supporting information). The similarity between divergence times and associated confidence intervals estimated in BEAST and DAMBE corroborates the results from the simulation study by Xia and Yang (2011) suggesting that the latter method is not only very simple and extremely fast, but also accurate. 

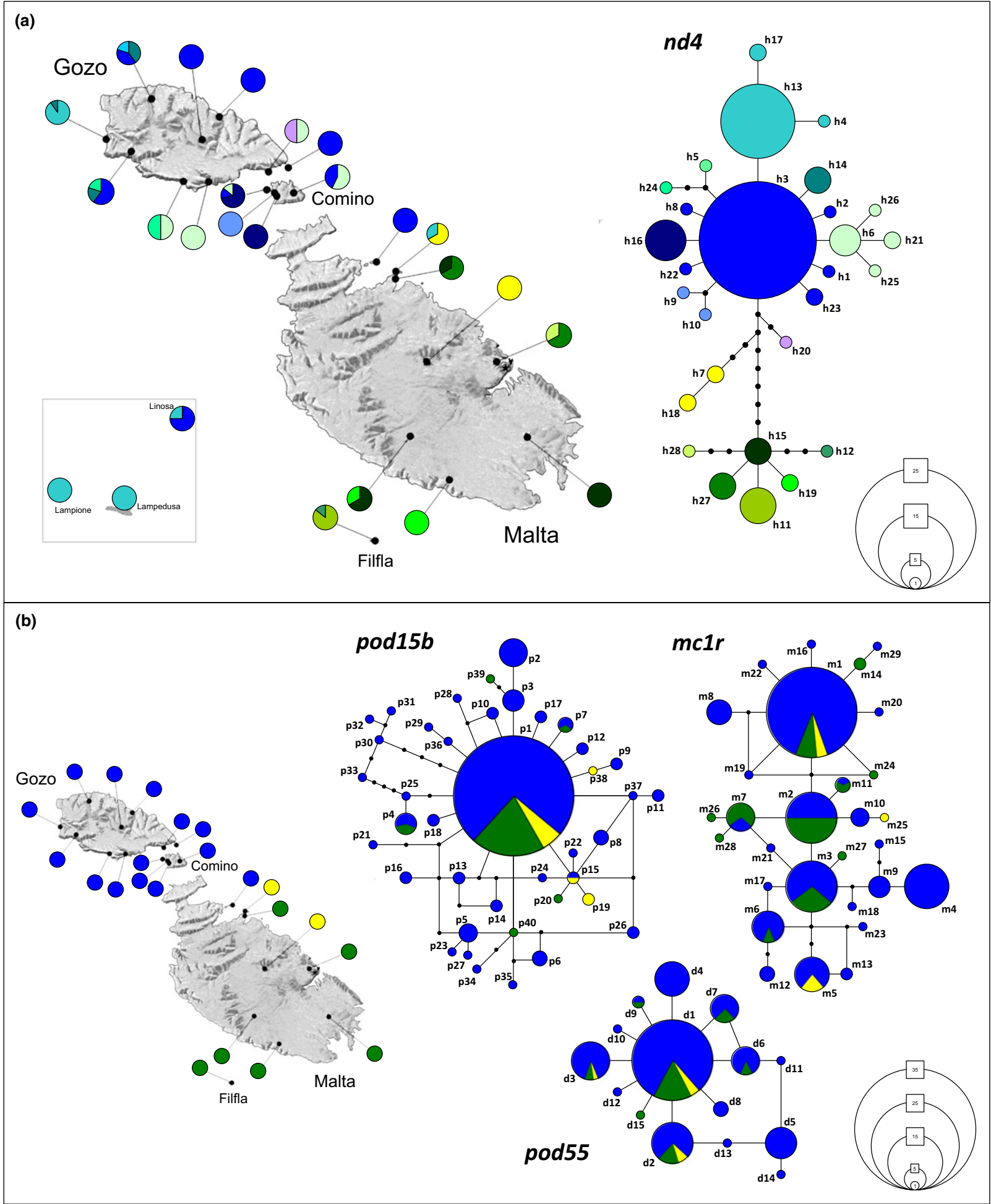

Fig. 2 Geographical distribution and genealogical relationships between the mitochondrial ( $n d 4$ : box a) and the nuclear (mc1r, pod15b and pod55: box b) haplotypes of Podarcis filfolensis. In the map of box a, pie diagrams show the geographical distribution and frequencies of haplotypes in each population; in the map of box $b$, the populations are coloured according to the geographic distribution of the main mitochondrial lineages as presented in box a. Statistical parsimony networks show the phylogenetic relationships between the haplotypes, which are represented by circles with size proportional to their frequencies and with small filled circles representing 'missing' or extinct haplotypes (right). For geographical details on sampling locations, see Table 1, for sample sizes, codes and frequencies of the mitochondrial and nuclear haplotypes see Table 2. 


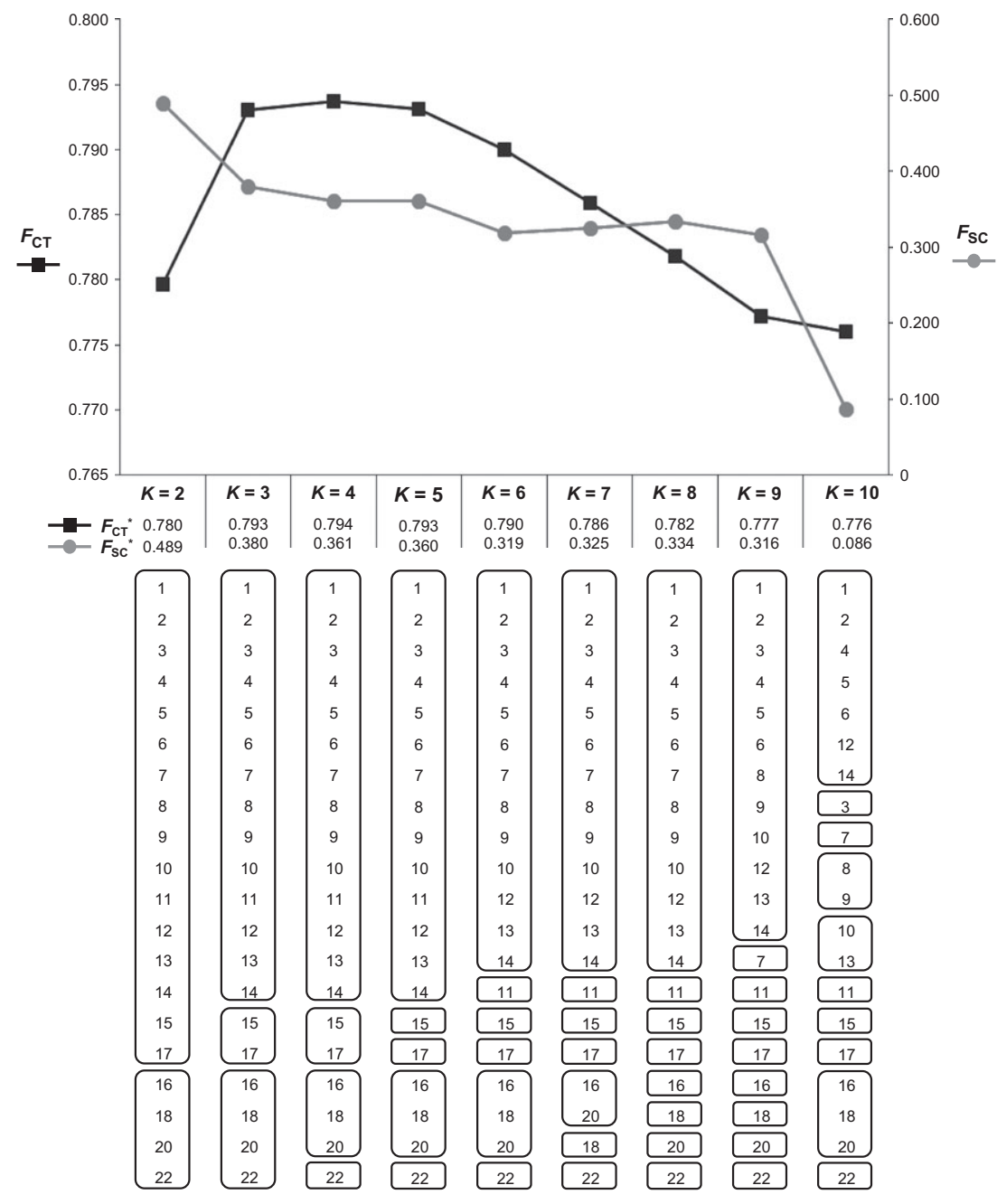

Fig. 3 Summary of results of spatial analysis of mitochondrial molecular variance (mtDNA SAMOVA) in Podarcis filfolensis populations. Associated with each predefined value of $K$ from 2 to 10 is reported the group composition for the best clustering option and relative fixation indices $F_{\mathrm{CT}}$ and $F_{\mathrm{SC}}(P<0.001)$.
The results from EBSP indicate that the Gozitan clade experienced a demographic expansion during the last 110 kya (see Fig. 4B). The occurrence of a historical population expansion for this clade was also supported by significant $D, F_{\mathrm{S}}$ and $R_{2}$ values (as well as their sign and magnitude) and by the mismatch analyses (see Fig. S3, Supporting information). The observed mismatch distribution was not significantly different from that expected either under a pure demographic expansion model (SSD $=0.005 ; P=0.153$ ), or under a sudden spatial expansion model $(\mathrm{SSD}=0.005 ; P=0.095)$. Given the value of parameter $\tau$ and the mutation rate estimated in DAMBE, considering the generation time of Podarcis species (estimated mean generation time = 2.09 years; Galán 1999; see also Barbault \& Mou 1988; Galán 1996; Adamopoulou \& Valakos 2000), the time since the spatial-demographic expansion of the Gozitan clade is estimated to have occurred during the first half of the last glacial period ( $83 \mathrm{kya}$; confidence interval: 59-114 kya).
For the Maltese clade, the EBSP shows a trend of recent expansion from 100 to $20 \mathrm{kya}$ (see Fig. 4C). The posterior probability of the number of demographic changes was the highest when it was 1, and 95\% credible intervals (HPD) excluded 0 for all runs thus rejecting the hypothesis of a constant population size. However, the wide credibility intervals suggest that the signal is not strong. Also the mismatch distribution is consistent with that expected under a model of population expansion (SSD $=0.019 ; P=0.192$ ). On the other hand, the nonsignificant $D, F_{\mathrm{S}}$ and $R_{2}$ values (as well as their sign and magnitude) suggested a history of demographic stability (see Fig. S4, Supporting information).

\section{Discussion}

The evolutionary history and historical demography of the Maltese wall lizard, as inferred from its pattern of genetic diversity, provide insights on how this species coped with Pleistocene palaeoecological and 
palaeogeographical changes. Furthermore, these findings have direct implications in the context of the island biogeography of the Maltese archipelago, as well as for the application of the EC model in coastal settings and refugial areas. The evolutionary history of $P$. filfolensis is therefore discussed in the context of these issues.

\section{Evolutionary history of Podarcis filfolensis}

The phylogenetic network and the spatial analysis of molecular variance show the existence of two main mitochondrial phylogroups within Podarcis filfolensis: one occurring on the island of Malta and its satellite islet Filfla (Maltese lineage) and the other one mainly distributed in the northern islands of the Maltese archipelago (Gozo and Comino islands and their surrounding islets) and in the Pelagian islands (Gozitan lineage) (Fig. 1). Two haplotypes found in four lizards from Malta were fairly differentiated from both these lineages (in yellow, in Fig. 2). They may represent a poorly sampled mitochondrial clade endemic to NE Malta or an ancestral polymorphism perhaps from an ancient Gozitan stock (currently extinct) that expanded to Malta during an early glacial stage. The low frequency of these haplotypes and their occurrence in only two nonadjacent sites led us to consider them as the result of the retention of an ancestral polymorphism rather than as a further phylogeographical group, but more sampling is needed to address this issue.

In contrast to mitochondrial data, nuclear sequence data do not show any phylogeographical structure across the study area. Indeed, the nuclear genetic patterns of $P$. filfolensis show high diversity, shallow haplotype divergence and no significant differences in haplotype frequencies between populations, suggesting a low divergence rate and historically high effective population size of nuclear markers. Thus, difference in rates of lineage sorting due to the fourfold difference in effective population sizes between the haploid, uniparentally inherited mitochondrial genome and the nuclear genome may explain their discordant patterns (Brown et al. 1979; Moore 1995; Hare 2001) as already reported in several phylogeographical studies based on nuclear and mitochondrial sequence data (Toews \& Brelsford 2012; Bisconti et al. 2013; Salvi et al. 2013). Alternative explanations for the observed cytonuclear discordance could be either sex-biased gene flow with stronger female phylopatry (e.g. Ujvari et al. 2008; reviewed in Prugnolle \& Meeus 2002) or stochastic processes acting on mtDNA and generating a spurious phylogeographical break (Irwin 2002); however, both seem unlikely in this case. Indeed, the fact that the main lineages are endemic to different islands makes it highly improbable that the observed phylogeographical break arose as a consequence of a stochastic process rather than as result of allopatric divergence. Moreover, although in Podarcis lizards, males usually disperse more than females (e.g. Vignoli et al. 2012), in the case of $P$. filfolensis, it is hard to believe that while females carrying Gozitan haplotypes would have moved only a few kilometres (approximately $20 \mathrm{~km}$, cf. samples 14-15 in NE Malta) during a hundred thousand years, during the same period males have been extensively carrying nuclear alleles between the Gozitan and the Maltese compartments. Therefore, although male-biased gene flow may have contributed to the observed pattern, considering the relatively recent estimated time frame for the mitochondrial divergence between the two lineages (see below), a failure of the nuclear markers to diverge and differentiate appears the most plausible hypothesis for the observed genetic patterns (Palumbi et al. 2001; Hudson \& Turelli 2003; Toews \& Brelsford 2012). Data from hypervariable nuclear markers, such as microsatellites, may help in reaching a firm conclusion on this issue.

The coalescence time of the mitochondrial lineages and their divergence dates back to the Middle Pleistocene (around 500 kya; Fig. S2, Supporting information). The most prominent driver for the palaeogeographical and palaeoenvironmental evolution of the Maltese archipelago during the entire Pleistocene was undoubtedly associated with sea-level changes due to glacialinterglacial cycles. In particular, in the Maltese archipelago interglacials were occasions for allopatric divergence for those species having limited over-sea dispersal ability such as lizards, as their populations were separated on different islands by rising sea level (see e.g. Pedley 2011). Remarkably, interglacial periods prior to 480 kya were apparently longer and colder than the typical interglacials of the latest Quaternary, as documented by palaeoclimatic records (EPICA Community Members 2004). Thus, a prolonged isolation on distinct islands of the Maltese palaeoarchipelago during the Middle Pleistocene seems a particularly plausible scenario for the allopatric divergence between the main lineages of $P$. filfolensis.

The geographical distribution of the Gozitan and the Maltese lineages and their estimated divergence time suggest that these lineages from the Middle Pleistocene survived the climatic oscillations in separate refugia in the northern and in the southern portion of the Maltese archipelago, respectively. However, while during interglacial periods, these lineages were likely confined on distinct islands, during glacial periods the wide connection between Maltese islands suggests that these lineages would have had occasion for demographic and range expansion, and admixture following secondary contact. 
The historical demographic analyses based on four independent assessments consistently indicate a marked population and spatial expansion of the Gozitan lineage during the last glacial period (Fig. 4B; Fig. S3, Supporting information). According to the palaeogeographical reconstruction of the Maltese archipelago based on high-resolution seafloor geological data (Micallef et al. 2013; see also Pedley et al. 2002), there was a noticeable increase in the size of Gozo island during this period, which was merged with Comino and Malta in a single macro-island because of the glaciation-induced sea-level drop. As a consequence of such marine regression, newly exposed lowlands were readily available for colonization by terrestrial organisms from all over the palaeo-Maltese landmass and in particular a wide expanse of coastal plain extended on the eastern side (Figs 4A and 5). This area might not only have provided for larger effective population sizes of insular lineages due to an increased carrying capacity, but might also have allowed their spatial expansion. The finding of haplotypes of the Gozitan lineage in two localities in what is now northeasternmost Malta (Selmunett Islet and Ta' Fra Ben, samples 14-15) and the inferred pattern and timing of demographic and spatial expansion for this lineage closely fits in this scenario. This hypothesis is preferable over the alternative explanation of a recent introduction of Gozitan lizards in NE Maltese localities because there we observed multiple haplotypes, in Selmunett Islet also private haplotypes (h22 and h23), and because the human-mediated arrival of Gozitan lizards in this small islet off Malta would have required a two-step introduction process.

The historical demography of the Maltese lineage as inferred by mismatch and EBPS analyses also shows a trend of recent expansion during the last glacial period, but neutrality test statistics did not recover a signal of such a demographic event (Fig. 4C; Fig. S3, Supporting information). Within this group, we observed a strong population differentiation with only one fairly widespread haplotype (h15) and all others being private to one or two populations. Population fragmentation patterns such as this can hinder the detection of past demographic (and spatial) expansion leading to a signal of population stability in mismatch distribution analysis and neutrality test statistics (Wakley 1999; Hein et al. 2005; Chikhi et al. 2010); therefore, the hypothesis of demographic expansion cannot be rejected for the Maltese lineage.

On the other hand, the lack of evidence for admixture between Maltese and Gozitan lineages suggests that even if both these lineages would have undergone spatial expansions during the last glacial period, demographic exchange between them was still limited. Moreover, the occurrence of two spatially structured
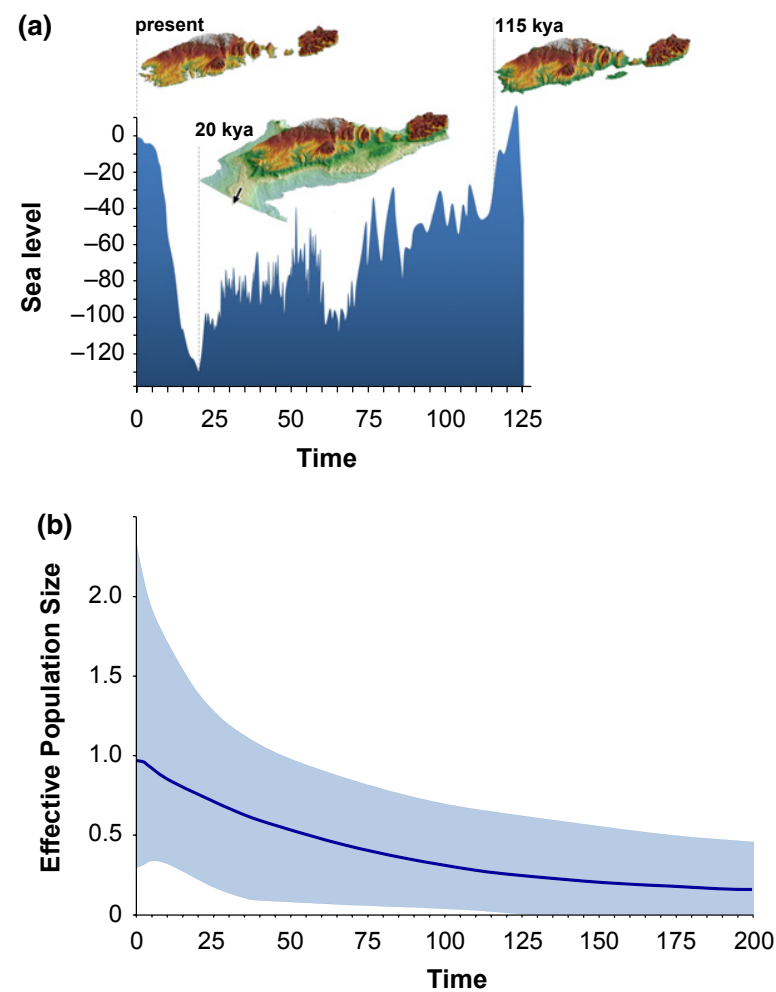

(c)

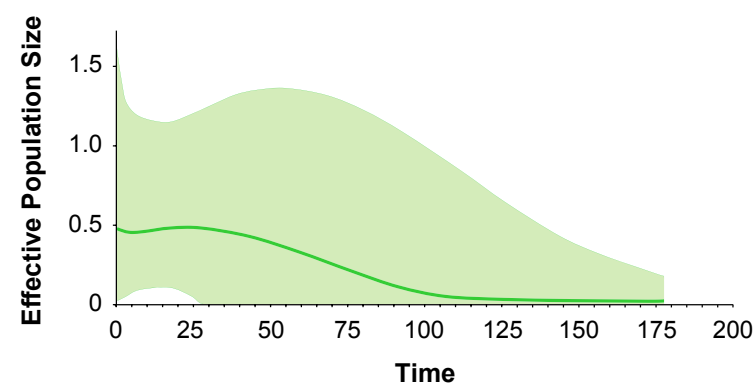

Fig. 4 Sea-level changes during the last 125 kya (redrawn from Siddall et al. 2003 and Lambeck et al. 2011) and associated 3D Maltese palaeoshorelines reconstructed based on high-resolution seafloor geological data (from Micallef et al. 2013) (box a). Historical demographic analysis for the Gozitan (box b) and the Maltese (box c) lineages of Podarcis filfolensis as inferred by Extended Bayesian Skyline Plot analyses; along the $y$-axis the effective population sizes are expressed in units of $\mathrm{N}_{\mathrm{e}} \tau$ the product of the effective population size per generation length. Solid lines are median estimates, whereas shaded areas represent confidence intervals; prior to $200 \mathrm{kya}$, the demographic function for the Gozitan lineages (box b) contains few $x$-axis points (data not shown), and so not enough power to pinpoint the exact population size value.

mitochondrial lineages suggests that admixture between these lineages can be ruled out for previous glacial periods as well. Indeed, simulations of coalescence under an island model of population subdivision show that the formation of geographically confined clusters of mitochondrial haplotypes is prevented by even very 


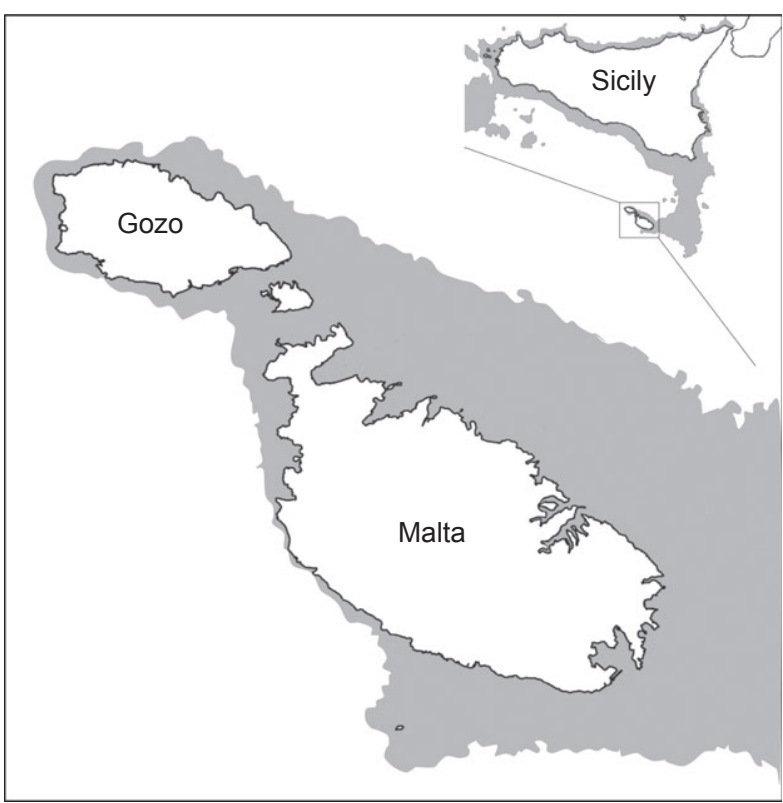

Fig. 5 The coastline of the Maltese Islands and Sicily during the Last Glacial Maximum (redrawn from Pedley 2002 and Micallef et al. 2013)

low levels of dispersal between them (Papadopoulou et al. 2008).

\section{Island biogeography of the Maltese archipelago}

The inferred evolutionary history of $P$. filfolensis has at least three important implications for the biogeography of the Maltese archipelago. First, the estimated coalescence time for the mitochondrial haplotypes of $P$. filfolensis dates back to the Middle Pleistocene. Thus, although the genetic variability accumulated prior to that time became extinct without any direct contribution to modern genetic lineages, this species exhibits genetic signatures of long-term persistence in the Maltese palaeoarchipelago throughout a series of full glacial/interglacial cycles since at least the Middle Pleistocene. In keeping with the prediction that in Mediterranean islands, the climatic buffering of the sea may have provided suitable habitats for stable populations throughout the Quaternary (Médail \& Diadema 2009), the present study shows that at least two main areas Gozo and Malta - within the Maltese archipelago acted as 'long-term refugia'.

Second, the inferred evolutionary and demographic history of $P$. filfolensis points to a major role of Pleistocene sea-level fluctuations, rather than of direct effects of climate changes, in the formation and distribution of intraspecific genetic diversity. According to available palaeontological data, sea-level changes shaped the assembly and evolution of the entire Maltese biota (reviewed in Hunt \& Schembri 1999; Pedley et al. 2002, 2007; Schembri 2003). Interestingly, while interglacial high-stands primed the allopatric differentiation between populations from Gozo and Malta, on the other hand despite these islands being extensively connected during glacial low-stands, demographic and genetic interchange between their populations was limited, suggesting that the Gozitan and Maltese compartments evolved as independent biotic units during the Pleistocene.

Third, the genetic analysis of lizards from the Maltese and the Pelagian archipelagos provides useful information on biotic exchange between islands across the Sicilian Channel. Lizards from the Pelagian islands (samples 23-25) carry exclusively mitochondrial haplotypes of the Gozitan lineage and in particular those having the highest frequency on Gozo (h3 and h13, Fig. 2). The small population of Lampedusa has been introduced in the last decade from nearby Linosa (Lo Cascio et al. 2005), while the haplotype composition and the low genetic diversity of Lampione and Linosa (see Table 3) suggest that $P$. filfolensis colonized the Pelagian islands from the Maltese archipelago in historical times as argued by Capula (1994a) based on allozyme data. Furthermore, our data clearly indicate Gozo as the most probable source island for this colonization. Although the Pelagian and the Maltese archipelagos shared most of their early geological origin as part of the Pelagian block (Pedley et al. 1978; Grasso \& Pedley 1985; Pedley 1990; Gatt 2007), they have had independent histories since the end of the Messinian Salinity Crisis during the Miocene (approximately 5.33 Mya; Krijgsman et al. 1999; Pierre et al. 2006), as the deep sea channel between them (up to $1000 \mathrm{~m}$ ) prevented their connection during the Plio-Pleistocene marine regressions (Pedley et al. 2002). Thus, for the Pelagian P. filfolensis populations, an origin through long-distance rafting or human transportation is suggested (see Capula 1994a). Although it is difficult to disentangle whether this species colonized the Pelagian Islands by natural means or through human agency, the latter scenario seems more plausible considering the small size of the Pelagian islands (and thus low colonization rates) and in the light of the pattern of interisland variation observed within the Maltese archipelago, which clearly indicates very limited over-sea dispersal for $P$. filfolensis.

\section{Perspectives on the EC model of Pleistocene biogeography}

The Maltese archipelago and the endemic lizard P. filfolensis present a simplified experiment for testing two key predictions of the EC model: (i) temperate species experienced a maximum demographic/spatial 
contraction during glacial stages and (ii) the high level of intraspecific genetic diversity harboured in glacial refugia is a direct consequence of the persistence of large and demographically stable populations.

The inferred evolutionary and demographic history of $P$. filfolensis clearly does not fit the prediction from the EC model of populations of temperate species contracting in refugia during glacials. This basic prediction is based on the scenario whereby during glacials, as a consequence of global cooling, temperate species suffered a global reduction of habitat availability. However, this model, mainly centred around the terrestrial biota of continental Europe, does not account for geographical settings such as found in coastal areas where (local) climate conditions were not too severe during glacials, and terrestrial habitat availability dramatically increased as a consequence of glacio-eustatic sea-level lowering (Thiede 1978; Rohling et al. 1998). In these conditions, a converse EC response for populations of temperate species may be expected throughout the Pleistocene cycles with glacial (demographic/spatial) expansions during sea-level low-stands and interglacial contractions owing to contraction of islands size. Apart from $P$. filfolensis, glacial expansion of temperate species has been recently inferred for populations occurring in coastal lowlands both in Mediterranean islands (Bisconti et al. 2011) and in continental setting (Canestrelli et al. 2007; Canestrelli \& Nascetti 2008). Similarly to P. filfolensis, in the tree frog Hyla sarda endemic to (Tyrrhenian) Mediterranean islands, the estimated time since the expansion was placed in the first half of the glacial period (Bisconti et al. 2011) during a period well known for rapid and extensive glacio-eustatic sea-level lowering (of nearly $-50 \mathrm{~m}$ between 80 and $70 \mathrm{kya}$; Ruddiman et al. 1980; Shackleton 1987; Larsen \& Sejrup 1990). In the mainland species Hyla intermedia and Pelophylax lessonae, genetic data suggest that demographic expansions might have occurred in coastal refugial areas of the NE Italian Peninsula where the glaciation-induced increases in the extent of coastal plains overcame the negative demographic effects of glacial climate (Canestrelli et al. 2007; Canestrelli \& Nascetti 2008). In all these cases, the scenario of glacial expansion of coastal populations is supported by independent evidence from palaeogeographical, sedimentological, palaeontological (fossil and pollen) and palaeodistribution model data (see references in Canestrelli et al. 2007; Canestrelli \& Nascetti 2008; Bisconti et al. 2011). Moreover, spatial expansions of temperate species during glacial marine regressions have recurrently been invoked to explain dispersal of temperate species between islands of Mediterranean archipelagos and/or with the continent (e.g. Fattorini 2002; Salvi et al. 2011; Garnatje et al. 2012; Rodriguez et al. 2013; see also Thompson 2005; Blondel et al. 2010).
Thus, notwithstanding that the ranges and populations of temperate species have had an expansion-contraction response to Pleistocene climatic change, to predict the timing of these EC dynamics it is necessary to extend the simple EC model for continental species by including the relative effect of climate and sea-level variations on habitat availability. Although a considerably smaller number of studies have been made on coastal/insular populations compared with continental populations, data available up to now strongly suggest that the balance between these effects seems to have had an opposite EC outcome during glacial periods for Western Palaearctic temperate species in coastal as compared to continental ecosystems.

Archipelagos such as the ones studied here offer various insights for understanding what processes were triggered by these EC dynamics and what consequences those processes had on the genetic diversity pattern of temperate species within Pleistocene refugia. The genetic variation observed within $P$. filfolensis is mostly accounted for by the differentiation between two main lineages (79\%, Fig. 3) primed by the allopatric fragmentation of the Maltese archipelago during Pleistocene cycles. The evolutionary independence of these lineages was maintained also during glacial stages, despite the islands of this archipelago being merged together in a macro-island of increased surface area and the sea buffering considerably the Maltese climate during periods of cooling (Schembri 1997; Hunt \& Schembri 1999). Thus, the evolutionary history of $P$. filfolensis supports a major role for allopatric fragmentation in the formation of the observed genetic diversity, while the habitat availability and the long-term stability of Maltese climate during glacials would account for the maintenance of such diversity and for the narrow secondary admixture following parapatric contact between lineages. When considering the relevance of the processes of allopatric divergence in the context of the formation of intraspecific diversity, the processes inferred for $P$. filfolensis or other insular systems (e.g. Jordan et al. 2005) provide interesting analogues to the processes taking place in Pleistocene glacial refugia. Studies carried out in well-established glacial refugia such as the three Mediterranean peninsulas - Iberia, Italy and the Balkan - suggest that in various species, including amphibians, reptiles and mammals, the high intraspecific diversity observed arose because of allopatric divergence of populations from multiple subrefugia occurring within the main refugial areas, rather than as a direct outcome of prolonged stability of large populations within these areas (e.g. Martínez-Solano et al. 2006; Sotiropoulos et al. 2007; Ursenbacher et al. 2008; Vega et al. 2010; Miraldo et al. 2011; Canestrelli et al. 2012; for an overview see Tzedaki 2009; and Nieto 
Feliner 2011). In the specific case of southern Italy, EC dynamics until the Middle Pleistocene were indeed associated with the palaeoinsularization of the current mountain massifs of this main refugial area (Canestrelli et al. 2010; Vega et al. 2010). Here, genetic signatures of allopatric isolation and differentiation have been documented also across small geographical scales, in some of which demographic and spatial expansion of allopatric lineages promoted their secondary admixture generating a melting pot of diversity (Canestrelli et al. 2010). Building on this evidence and on the well-established paradigm of refugia-within-refugia (Gómez \& Lunt 2007), the cross-archipelago pattern shown in this study illustrates a general model in which genetic diversity is formed and shaped by cycles of allopatric divergence and repeated contact driven by population EC dynamics acting within highly compartmentalized refugia.

\section{Conclusion}

Since Darwin's first formulation, islands have been used as natural laboratories for developing and testing ecological and evolutionary theories (Darwin 1859; Whittaker \& Fernández-Palacios 2007). Indeed, being discrete and isolated spatial entities surrounded by an inhospitable matrix, islands permit a number of simplifying assumptions to be made in empirical and theoretical models, which are relevant also to mainland geographical analogues such as patchy terrestrial and freshwater habitats (MacArthur \& Wilson 1967; Whittaker \& Fernández-Palacios 2007; but see also Walter 2004).

However, although Mediterranean islands have long been identified as key hotspots and glacial refugia for biodiversity (e.g. Médail \& Quézel 1999; Médail \& Diadema 2009), they have never been considered in empirical and theoretic models of Pleistocene phylogeography (Dapporto et al. 2009). This study corroborates the huge significance of Mediterranean archipelagos for testing, refining and extending these models and also as a simplified setting for studying the evolutionary and demographic processes responsible for the high diversity patterns observed within glacial refugia.

When combined with recent literature on island and coastal populations, the case study of $P$. filfolensis shows how the incorporation of Pleistocene sea-level variations in the EC model allows prediction of a reverse demographic and range response of insular and coastal temperate biotas relative to those of the continent. What is more, the Mediterranean archipelago here studied represents a simplified model of glacial refugia in which allopatric diversity is formed and shaped by cyclic contraction-expansion of habitats during the Pleistocene. A similar scenario has been invoked by a growing number of phylogeographical studies to explain the high genetic diversity of populations from mainland refugia, suggesting a key role of the Pleistocene EC dynamics in shaping the pattern of genetic diversity of temperate species not only into and out-of refugia but also within these areas.

\section{Acknowledgements}

This article is dedicated to the memory of our colleague H.S. Robert Glaser formerly of the Institut für Biochemie, JustusLiebig-Universität, Giessen, Germany, who passed away in May 2010. He encouraging us to undertake this study and was instrumental in setting it up; he also financed some collecting trips to the smaller islands of the Maltese group. We thank John Stewart, Martyn Pedley, Sara Rocha, Catarina Pinho, Xuhua Xia, Daniele Canestrelli and the anonymous reviewers for useful suggestions. This study was funded by the Project 'Genomics and Evolutionary Biology' cofinanced by North Portugal Regional Operational Programme 2007/2013 (ON.2-O Novo Norte), under the National Strategic Reference Framework (NSRF), through the European Regional Development Fund (ERDF); by the the FCT projects PTDC/BIA-BDE/74349/ 2006 (to DJH) from Fundação para a Ciência e a Tecnologia (FCT, Portugal) and by the University of Malta (to PJS). DS is supported by the FCT post-doctoral grant SFRH/BPD/66592/ 2009 and by the SYNTHESYS Project http://www.synthesys. info/ which is financed by European Community Research Infrastructure Action under the FP7 Capacities Programme at the Museo Museo Nacional de Ciencias Naturales of Madrid (CSIC). This work conforms fully to the laws of Malta and we thank the Malta Environment and Planning Authority for granting permits to work on the protected Maltese wall lizard.

\section{References}

Adamopoulou C, Valakos ED (2000) Small clutch size in a Mediterranean endemic lizard. Copeia, 2, 610-614.

Arévalo E, Davis SK, Sites JW (1994) Mitochondrial DNA sequence divergence and phylogenetic relationships among eight chromosome races of the Sceloporus grammicus complex (Phrynosomatidae) in central Mexico. Systematic Biology, 43, 387-418.

Bandelt H-J (2008) Time dependency of molecular rate estimates: tempest in a teacup. Heredity, 100, 1-2.

Barbault R, Mou Y-P (1988) Population dynamics of the common wall lizard, Podarcis muralis, in southwestern France. Herpetologica, 44, 38-47.

Bennett KD, Tzedakis PC, Willis KJ (1991) Quaternary refugia of northern European trees. Journal of Biogeography, 18, $103-115$.

Bisconti R, Canestrelli D, Colangelo P et al. (2011) Multiple lines of evidence for demographic and range expansion of a temperate species (Hyla sarda) during the last glaciation. Molecular Ecology, 20, 5313-5327.

Bisconti R, Canestrelli D, Salvi D et al. (2013) A geographic mosaic of evolutionary lineages within the insular endemic newt Euproctus montanus. Molecular Ecology, 22, 143-156. 
Blondel J, Aronson J, Bodiou JY et al. (2010) The Mediterranean Region: Biological Diversity in Space and Time, 2nd edn. Oxford University Press, New York, NY.

Brown WM, George M Jr, Wilson AC (1979) Rapid evolution of animal mitochondrial DNA. Proceedings of the National Academy of Sciences of the United States of America, 76, 1967-1971.

Brown RP, Terrasa B, Pérez-Mellado V et al. (2008) Bayesian estimation of post-Messinian divergence times in Balearic Island lizards. Molecular Phylogenetics and Evolution, 48, 350358.

Bruen T, Phillipe H, Bryant D (2006) A quick and robust statistical test to detect the presence of recombination. Genetics, 172, 2665-2681.

Canestrelli D, Nascetti G (2008) Phylogeography of the pool frog Rana (Pelophylax) lessonae in the Italian peninsula and Sicily: multiple refugia, glacial expansions and nuclearmitochondrial discordance. Journal of Biogeography, 35, 1923-1936.

Canestrelli D, Cimmaruta R, Nascetti G (2007) Phylogeography and historical demography of the Italian treefrog Hyla intermedia reveals multiple refugia, population expansions and secondary contacts within peninsular Italy. Molecular Ecology, 16, 4808-4821.

Canestrelli D, Aloise G, Cecchetti S et al. (2010) Birth of a hotspot of intraspecific genetic diversity: notes from the underground. Molecular Ecology, 19, 5432-5451.

Canestrelli D, Salvi D, Maura M et al. (2012) One Species, three Pleistocene evolutionary histories: phylogeography of the Italian crested newt, Triturus carnifex. PLoS One, 7, e41754.

Capula M (1994a) Evolutionary relationships of Podarcis lizards from Sicily and the Maltese Islands. Journal of Zoological Systematics and Evolutionary Research, 32, 180-192.

Capula M (1994b) Genetic variation and differentiation in the lizard, Podarcis wagleriana (Reptilia: Lacertidae). Biological Journal of the Linnean Society, 52, 177-196.

Chikhi L, Sousa VC, Luisi P et al. (2010) The confounding effects of population structure, genetic diversity and the sampling scheme on the detection and quantification of population size changes. Genetics, 186, 983-995.

Clement M, Posada D, Crandall KA (2000) TCS: a computer program to estimate gene genealogies. Molecular Ecology, 9, 1657-1660.

Dapporto L, Bruschini C, Baracchi D et al. (2009) Phylogeography and counter-intuitive inferences in island biogeography: evidence from morphometric markers in the mobile butterfly Maniola jurtina (Linnaeus) (Lepidoptera, Nymphalidae). Biological Journal of the Linnean Society, 98, 677-692.

Darriba D, Taboada GL, Doallo R, Posada D (2012) jModelTest 2: more models, new heuristics and parallel computing. Nature Methods, 9, 772.

Darwin C (1859) On the Origin of Species. John Murray, London.

Drummond AJ, Suchard MA, Xie D, Rambaut A (2012) Bayesian phylogenetics with BEAUti and the BEAST 1.7. Molecular Biology and Evolution, 29, 1969-1973.

Dupanloup I, Schneider S, Excoffier L (2002) A simulated annealing approach to define the genetic structure of populations. Molecular Ecology, 11, 2571-2581.

EPICA Community Members (2004) Eight glacial cycles from an Antarctic ice core. Nature, 429, 623-628.
Excoffier L (2004) Patterns of DNA sequence diversity and genetic structure after a range expansion: lessons from the infinite-island model. Molecular Ecology, 13, 853-864.

Excoffier L, Lischer HEL (2010) Arlequin suite ver 3.5: a new series of programs to perform population genetics analyses under Linux and Windows. Molecular Ecology Resources, 10, 564-567.

Fattorini S (2002) Biogeography of the tenebrionid beetles (Coleoptera, Tenebrionidae) on the Aegean Islands (Greece). Journal of Biogeography, 29, 49-67.

Fu Y-X (1997) Statistical tests of neutrality against population growth, hitchhiking and background selection. Genetics, 147, 915-925.

Galán P (1996) Sexual maturity in a population of the lacertid lizard Podacis bocagei. Herpetological Journal, 6, 87-93.

Galán P (1999) Demography and population dynamics of the lacertid lizard Podarcis bocagei in north-west Spain. Journal of Zoology, 249, 203-218.

Garnatje T, Pérez-Collazos E, Pellicer J et al. (2012) Balearic insular isolation and large continental spread framed the phylogeography of the western Mediterranean Cheirolophus intybaceus s.l. (Asteraceae). Plant Biology, 15, 166-175.

Gatt PA (2007) Controls on Plio-Quaternary foreland sedimentation in the region of the Maltese Islands. Bollettino Della Società Geologica Italiana, 126, 119-129.

Gómez A, Lunt DH (2007) Refugia within refugia: patterns of phylogeographic concordance in the Iberian Peninsula. In: Phylogeography in Southern European Refugia: Evolutionary Perspectives on the Origins and Conservation of European Biodiversity (eds Weiss S \& Ferrand N), pp. 155-188. Springer Verlag, Dordrecht.

Grasso M, Pedley HM (1985) The Pelagian Islands: a new geological interpretation from sedimentological and tectonic studies and its bearing on the evolution of the Central Mediterranean Sea (Pealgian Block). Geologica Romana, 24, $13-44$.

Hall TA (1999) BioEdit: a user-friendly biological sequence alignment editor and analysis program for Windows 95/98/ NT. Nucleic Acids Symposium Series, 41, 95-98.

Hare MP (2001) Prospects for nuclear gene phylogeography. Trends in Ecology \& Evolution, 16, 700-706.

Harris DJ, Pinho C, Carretero MA et al. (2005) Determination of genetic diversity within the insular lizard Podarcis tiliguerta using mtDNA sequence data, with a reassessment of the phylogeny of Podarcis. Amphibia-Reptilia, 26, 401-407.

Hein J, Schierup MH, Wiuf C (2005) Gene Genealogies, Variation and Evolution: A Primer in Coalescent Theory. Oxford University Press, Oxford.

Heled J (2010) Extended Bayesian skyline plot tutorial. Available from http://beast-mcmc.googlecode.com/svn-history/ r3936/trunk/doc/tutorial/EBSP/ebsp-tut.pdf.

Heled J, Drummond AJ (2008) Bayesian inference of population size history from multiple loci. BMC Evolutionary Biology, 8, 289.

Hewitt GM (1996) Some genetic consequences of ice ages and their role in divergence and speciation. Biological Journal of the Linnean Society, 58, 247-276.

Hewitt GM (2000) The genetic legacy of the Quaternary ice ages. Nature, 405, 907-913.

Hewitt GM (2004) The structure of biodiversity - insights from molecular phylogeography. Frontiers in Zoology, 1, 4. 
Hickerson MJ, Carstens BC, Cavender-Bares J et al. (2010) Phylogeography's past, present, and future: 10 years after Avise, 2000. Molecular Phylogenetics and Evolution, 54, 291-301.

Ho SYW, Phillips MJ, Cooper A, Drummond AJ (2005) Time dependency of molecular rate estimates and systematic overestimation of recent divergence times. Molecular Biology and Evolution, 22, 1561-1568.

Ho SYW, Shapiro B (2011) Skyline-plot methods for estimating demographic history from nucleotide sequences. Molecular Ecology Resources, 11, 423-434.

Hudson RR, Turelli M (2003) Stochasticity overrules the 'threetimes-rule': genetic drift, genetic draft and coalescence times for nuclear loci vs. mtDNA. Evolution, 57, 182-190.

Hunt CO, Schembri PJ (1999) Quaternary environments and biogeography of the Maltese islands. In: Facets of Maltese Prehistory (eds Mifsud A \& Savona Ventura C), pp. 41-75. The Prehistoric Society of Malta, Malta.

Huntley B, Birks HJB (1983) An Atlas of Past and Present Pollen Maps for Europe. Cambridge University Press, Cambridge.

Huson DH, Bryant D (2006) Application of phylogenetic networks in evolutionary studies. Molecular Biology and Evolution, 23, 254-267.

Irwin DE (2002) Phylogeographic breaks without geographic barriers to gene flow. Evolution, 56, 2383-2394.

Jordan S, Simon C, Foote D et al. (2005) Phylogeographic patterns of Hawaiian Megalagrion damselflies (Odonata: Coenagrionidae) correlate with Pleistocene island boundaries. Molecular Ecology, 14, 3457-3470.

Krijgsman W, Hilgen F, Raffi I et al. (1999) Chronology, causes and progression of the Messinian salinity crisis. Nature, 400, 652-654.

Lambeck K, Antonioli F, Anzidei M et al. (2011) Sea level change along the Italian coasts during Holocene and prediction for the future. Quaternary International, 232, 250-257.

Larsen E, Sejrup H-P (1990) Weichselian land-sea interaction; western Norway -Norwegian Sea. Quaternary Science Reviews, 9, 85-97.

Librado P, Rozas J (2009) DnaSP v5: a software for comprehensive analysis of DNA polymorphism data. Bioinformatics, 25, 1451-1452.

Lo Cascio P, Corti C, Billeci V et al. (2005) "First came, first served", or the recent introduced lizard populations of Lampedusa Island (S Italy). Programme and Abstracts of the 13th Ord. Meeting S.E.H., p. 72. Museum Koenig, Bonn.

MacArthur RH, Wilson EO (1967) The Theory of Island Biogeography. Princeton University Press, Princeton, New Jersey, USA.

Maramai A, Graziani L, Tinti S (2005) Tsunamis in the Aeolian Islands (southern Italy): a review. Marine Geology, 215, 11-21.

Martínez-Solano I, Teixeira J, Buckley D et al. (2006) Mitochondrial DNA phylogeography of Lissotriton boscai (Caudata, Salamandridae): evidence for old, multiple refugia in an Iberian endemic. Molecular Ecology, 15, 3375-3388.

Médail F, Diadema K (2009) Glacial refugia influence plant diversity patterns in the Mediterranean Basin. Journal of Biogeography, 36, 1333-1345.

Médail F, Quézel P (1999) Biodiversity hotspots in the Mediterranean Basin: setting global conservation priorities. Conservation Biology, 13, 1510-1513.

Micallef A, Foglini F, Le Bas T et al. (2013) The submerged paleolandscape of the Maltese Islands: morphology, evolu- tion and relation to Quaternary environmental change. Marine Geology, 335, 129-147.

Miraldo A, Hewitt GM, Paulo OS et al. (2011) Phylogeography and demographic history of Lacerta lepida in the Iberian Peninsula: multiple refugia, range expansions and secondary contact zones. BMC Evolutionary Biology, 11, 170.

Moore WS (1995) Inferring phylogenies from mtDNA variation: mitochondrial-gene trees versus nuclear-gene trees. Evolution, 49, 718-726.

Nieto Feliner G (2011) Southern European glacial refugia: a tale of tales. Taxon, 60, 365-372.

Palumbi SR, Cipriano F, Hare MP (2001) Predicting nuclear gene coalescence from mitochondrial data: the three-times rule. Evolution, 55, 859-868.

Papadopoulou A, Bergsten J, Fujisawa T et al. (2008) Speciation and DNA barcodes: testing the effects of dispersal on the formation of discrete sequence clusters. Philosophical Transactions of the Royal Society Series B - Biological Sciences, 363, 2987-2996.

Papadopoulou A, Anastasiou I, Keskin B et al. (2009) Comparative phylogeography of tenebrionid beetles in the Aegean archipelago: the effect of dispersal ability and habitat preference. Molecular Ecology, 18, 2503-2517.

Pedley HM (1990) Syndepositional tectonics affecting Cenozoic and Mesozoic deposition in the Malta and SE Sicily areas (Central Mediterranean) and their bearing on Mesozoic reservoir development in the $\mathrm{N}$ Malta offshore region. Marine and Petroleum Geology, 7, 171-180.

Pedley M (2011) The Calabrian Stage, Pleistocene highstand in Malta: a new marker for unravelling the Late Neogene and Quaternary history of the islands. Journal of the Geological Society, 168, 913-925.

Pedley HM, House MR, Waugh B (1978) The geology of the Pelagian Block: the Maltese Islands. In: The Ocean Basins and Margins, Vol 4B The Western Mediterranean (eds Nairn AEM, Kanes WH \& Stehli FG). Plenum Press, London.

Pedley M, Hughes Clarke M, Galea P (2002) Limestone Isles in a Crystal Sea: The Geology of the Maltese Islands. Publishers Enterprises Group, San Gwann, Malta.

Pedley HM, Grasso M, Maniscalco R et al. (2007) The Monte Carrubba Formation (Messinian, Sicily) and its correlatives: new light on basin-wide processes controlling sediment and biota distributions during the Palaeomediterranean-Mediterranean transition. Palaeogeography, Palaeoclimatology, Palaeoecology, 253, 363-384.

Pereira C, Couto A, Luís C et al. (2013) Twenty-one new sequence markers for population genetics, species delimitation and phylogenetics in wall lizards (Podarcis spp.). BMC Research Notes, 6, 299.

Pierre C, Caruso A, Blanc-Valleron M-M et al. (2006) Reconstruction of the paleoenvironmental changes around the Miocene-Pliocene boundary along a west-east transect across the Mediterranean. Sedimentary Geology, 188-189, 319-340.

Pinho C, Ferrand N, Harris DJ (2006) Reexamination of the Iberian and North African Podarcis (Squamata: Lacertidae) phylogeny based on increased mitochondrial DNA sequencing. Molecular Phylogenetics and Evolution, 38, 266-273.

Pinho C, Harris DJ, Ferrand N (2007) Contrasting patterns of population subdivision and historical demography in three western Mediterranean lizard species inferred from mitochondrial DNA variation. Molecular Ecology, 16, 1191-1205. 
Pinho C, Rocha S, Carvalho BM et al. (2010) New primers for the amplification and sequencing of nuclear loci in a taxonomically wide set of reptiles and amphibians. Conservation Genetic Resources, 2, 181-185.

Posada D, Crandall KA (2001) Intraspecific phylogenetics: trees grafting into networks. Trends in Ecology and Evolution, 16, $37-45$.

Poulakakis N, Lymberakis P, Valakos E et al. (2005) Phylogeography of Balkan wall lizard (Podarcis taurica) and its relatives inferred from mitochondrial DNA sequences. Molecular Ecology, 14, 2433-2443.

Provan J, Bennet KD (2008) Phylogeographic insights into cryptic glacial refugia. Trend in Ecology and Evolution, 23, 564-571.

Prugnolle F, Meeus T (2002) Inferring sex-biased dispersal from population genetic tools: a review. Heredity, 88, 161-165.

Rambaut A, Drummond AJ (2007) Tracer v1.5. Available from http:/ / beast.bio.ed.ac.uk/Tracer.

Ramos-Onsins SE, Rozas J (2002) Statistical properties of new neutrality tests against population growth. Molecular Biology and Evolution, 19, 2092-2100.

Rodriguez V, Brown RP, Terrasa B et al. (2013) Multilocus genetic diversity and historical biogeography of the endemic wall lizard from Ibiza and Formentera, Podarcis pityusensis (Squamata: Lacertidae). Molecular Ecology, 22, 4829-4841.

Rogers AR, Harpending H (1992) Population growth makes waves in the distribution of pairwise genetic differences. Molecular Biology and Evolution, 9, 552-569.

Rohling EJ, Fenton M, Jorissen FJ et al. (1998) Magnitudes of sea-level lowstands of the past 500,000 years. Nature, 394, 162-165.

Ruddiman WF, McIntyre A, Niebler-Hunt V et al. (1980) Oceanic evidence for the mechanism of rapid northern hemisphere glaciation. Quaternary Research, 13, 33-64.

Salvi D, Harris DJ, Bombi P et al. (2010) Mitochondrial phylogeography of the Bedriaga's rock lizard, Archaeolacerta bedriagae (Reptilia: Lacertidae) endemic to Corsica and Sardinia. Molecular Phylogenetics and Evolution, 56, 690-697.

Salvi D, Harris DJ, Perera A et al. (2011) Preliminary survey on genetic variation within the Pygmy Algyroides, Algyroides fitzingeri, across Corsica and Sardinia. Amphibia-Reptilia, 32, 281-286.

Salvi D, Harris DJ, Kaliontzopoulou A et al. (2013) Persistence across Pleistocene ice ages in Mediterranean and extra-Mediterranean refugia: phylogeographic insights from the common wall lizard. BMC Evolutionary Biology, 13, 147.

Sambrook J, Fritsch EF, Maniatis T (1989) Molecular Cloning: A Laboratory Manual, 2nd edn. Cold Spring Harbor Press, New York.

Savona Ventura C (1983) The herpetofauna of Comino and satellite islets with a note on the colouration of Podarcis filfolensis. Animalia, 10, 87-93.

Schembri PJ (1997) The Maltese Islands: climate, vegetation and landscape. GeoJournal, 41, 115-125.

Schembri PJ (2003) Current state of knowledge of the Maltese non-marine fauna. Malta Environment and Planning Authority Annual Report and Accounts 2003, pp. 33-65. Malta Environment and Planning Authority, Malta.

Schmitt T (2007) Molecular biogeography of Europe: Pleistocene cycles and postglacial trends. Frontiers in Zoology, 4, 11.

Schmitt T, Varga Z (2012) Extra-Mediterranean refugia: the rule and not the exception? Frontiers in Zoology, 9, 22.
Shackleton NJ (1987) Oxygen isotopes, ice volume and sea level. Quaternary Science Reviews, 6, 183-190.

Siddall M, Rohling EJ, Almogi-Labin A et al. (2003) Sea-level fluctuations during the last glacial cycle. Nature, 423, 853858.

Sotiropoulos K, Eleftherakos K, Džukić G et al. (2007) Phylogeny and biogeography of the alpine newt Mesotriton alpestris (Salamandridae, Caudata), inferred from mtDNA sequences. Molecular Phylogenetics and Evolution, 45, 211-226.

Stephens M, Donelly P (2003) A comparison of Bayesian methods for haplotype reconstruction from population genotype data. American Journal of Human Genetics, 73, 1162-1169.

Stephens M, Smith NJ, Donnelly P (2001) A new statistical method for haplotype reconstruction from population data. American Journal of Human Genetics, 68, 978-989.

Stewart JR, Dalén L (2008) Is the glacial refugium concept relevant for northern species? A comment on Pruett and Winker 2005. Climate Change, 86, 19-22.

Stewart JR, Lister AM (2001) Cryptic northern refugia and the origins of the modern biota. Trends in Ecology and Evolution, 16, 608-613.

Stewart JR, Lister AM, Barnes I et al. (2010) Refugia revisited: individualistic responses of species in space and time. Proceedings of the Royal Society Series B - Biological Sciences, 277, 661-671.

Taberlet P, Fumagalli L, Wust-Saucy A-G et al. (1998) Comparative phylogeography and postglacial colonization routes in Europe. Molecular Ecology, 7, 453-464.

Tajima F (1989) Statistical method for testing the neutral mutation hypothesis by DNA polymorphism. Genetics, 123, 585595.

Tamura K, Nei M, Kumar S (2004) Prospects for inferring very large phylogenies by using the neighbor-joining method. Proceedings of the National Academy of Sciences of the United States of America, 101, 11030-11035.

Tamura K, Peterson D, Peterson N et al. (2011) MEGA5: molecular evolutionary genetics analysis using maximum likelihood, evolutionary distance, and maximum parsimony methods. Molecular Biology and Evolution, 28, 2731-2739.

Thiede J (1978) A glacial Mediterranean. Nature, 276, 680-683.

Thompson JD (2005) Plant Evolution in the Mediterranean. Oxford University Press, New York.

Thompson JD, Higgins DG, Gibson TJ (1994) CLUSTAL W: improving the sensitivity of progressive multiple sequence alignment through sequence weighting, position specific gap penalties and weight matrix choice. Nucleic Acids Research, 22, 4673-4680.

Toews DP, Brelsford A (2012) The biogeography of mitochondrial and nuclear discordance in animals. Molecular Ecology, 21, 3907-3930.

Tzedaki PC (2009) Museums and cradles of Mediterranean biodiversity. Journal of Biogeography, 36, 1033-1034.

Ujvari B, Dowton M, Madsen T (2008) Population genetic structure, gene flow and sex-biased dispersal in frillneck lizards (Chlamydosaurus kingii). Molecular Ecology, 17, 35573564 .

Ursenbacher S, Schweiger S, Tomović L et al. (2008) Molecular phylogeny of the nose-horned viper (Vipera ammodytes, Linnaeus (1758)): evidence for high genetic diversity and multiple refugia in the Balkan peninsula. Molecular Phylogenetics and Evolution, 46, 1116-1128. 
Vega R, Amori G, Aloise G et al. (2010) Genetic and morphological variation in a Mediterranean glacial refugium: evidence from Italian pygmy shrews, Sorex minutus (Mammalia: Soricomorpha). Biological Journal of the Linnean Society, 100, 774-787.

Vignoli L, Vuerich V, Bologna MA (2012) Experimental study of dispersal behaviour in a wall lizard species (Podarcis sicula) (Sauria Lacertidae). Ethology Ecology \& Evolution, 24, 244256.

Wakley J (1999) Non equilibrium migration in human history. Genetics, 153, 1863-1871.

Walter HS (2004) The mismeasure of islands: implications for biogeographical theory and the conservation of nature. Journal of Biogeography, 31, 177-197.

Whittaker RJ, Fernández-Palacios JM (2007) Island Biogeography: Ecology, Evolution, and Conservation, 2nd edn. Oxford University Press, Oxford.

Williams D, Dunkerley D, De Deckker P et al. (1998) Quaternary Environments. Arnold, London.

Xia X (2009) Information-theoretic indices and an approximate significance test for testing the molecular clock hypothesis with genetic distances. Molecular Phylogenetics and Evolution, 52, 665-676.

Xia X, Xie Z (2001) DAMBE: software package for data analysis in molecular biology and evolution. Journal of Heredity, 92, 371-373.

Xia X, Yang Q (2011) A distance-based least-square method for dating speciation events. Molecular Phylogenetics and Evolution, 59, 342-353.

D.S., D.J.H. and P.J.S. designed the research; A.S. collected the samples; D.S. generated the sequence data, analysed the data, and drafted the article; D.J.H. and P.J.S. contributed reagents/materials and critically revised the manuscript; all authors read and approved the final manuscript.

\section{Data accessibility}

DNA sequences: GenBank accession numbers KJ027723-KJ027980; for each individual, details on sampling and the GenBank accession number for its sequence data uploaded as online supplemental material (Table S1, Supporting information). DNA sequence alignments: Dryad doi:10.5061/dryad.6hs29. DAMBE and BEAST dating analyses input files and output trees: Dryad doi:10.5061/dryad.6hs29.

\section{Supporting information}

Additional supporting information may be found in the online version of this article.

Table S1 Geographical location and codes for the studied specimens of Podarcis filfolensis and the outgroup species Podarcis wagleriana (*) and Podarcis raffonei (**).

Fig. S1 Results of Spatial Analysis of Molecular Variance (SAMOVA) analyses based on nuclear DNA data (loci $m c 1 r$, pod15b, and pod55).

Fig. S2 Chronogram showing the estimated times to the most recent common ancestor of the mitochondrial lineages of $P$. filfolensis.

Fig. S3 Historical demographic analysis for the two main mitochondrial lineages of Podarcis filfolensis. 